\title{
Advances in antiplatelet technologies to improve cardiovascular disease morbidity and mortality: a review of ticagrelor
}

This article was published in the following Dove Press journal:

Clinical Pharmacology:Advances and Applications

18 April 2013

Number of times this article has been viewed

\author{
Estella M Davis \\ Jon T Knezevich \\ Robyn M Teply \\ Department of Pharmacy Practice, \\ Creighton University School of \\ Pharmacy and Health Professions, \\ Omaha, NE, USA
}

\begin{abstract}
Antiplatelet therapy is widely used with proven benefit for the prevention of further ischemic cardiac complications in patients with acute coronary syndrome. Treatment guidelines for acute coronary syndrome and percutaneous coronary intervention now recommend the use of oral antiplatelet agents including ticagrelor, prasugrel, or clopidogrel in combination with aspirin to comprise dual antiplatelet therapy for the prevention of recurrent ischemic events. The limitations of conventional antiplatelet therapy with clopidogrel or prasugrel include the potential for low response to clopidogrel identified through platelet reactivity or genetic testing, increased risk of bleeding with prasugrel, or slower return to normal platelet activity in patients who received either prasugrel or clopidogrel prior to emergent or planned surgical procedures. This review will discuss the pharmacokinetic and pharmacodynamic properties of ticagrelor in comparison to conventional $\mathrm{P} 2 \mathrm{Y}_{12}$ receptor inhibitors and its utility in patients identified as low responders to clopidogrel. Completed clinical studies and substudies comparing ticagrelor to clopidogrel and ongoing clinical trials evaluating ticagrelor in acute coronary syndrome patients will also be reviewed.
\end{abstract}

Keywords: ticagrelor, antiplatelet, acute coronary syndrome, ST elevation myocardial infarction, non-ST elevation MI, percutaneous coronary intervention

\section{Introduction}

According to the most recent report from the World Health Organization, ischemic heart disease is the leading cause of death worldwide, accounting for 7.25 million deaths per year. ${ }^{1}$ Platelets play an important role in the pathophysiology of thrombus formation and stabilization after an atherosclerotic plaque rupture in conjunction with acute coronary syndrome., ${ }^{2,3}$ The release of adenosine diphosphate and subsequent stimulation of the platelet via the $\mathrm{P} 2 \mathrm{Y}_{12}$ receptor occurs early in this process. ${ }^{4}$ Further aggregation and activation of platelets occurs via stimulation of other receptors including glycoprotein IIb/IIIa.

Antiplatelet therapy including aspirin, $\mathrm{P}_{2} \mathrm{Y}_{12}$ inhibitors, and glycoprotein IIb/IIIa inhibitors are widely used with proven benefit for the prevention of further ischemic cardiac complications in these patients. Treatment guidelines for acute coronary syndrome (ACS) and percutaneous coronary intervention (PCI) recommend the use of dual antiplatelet therapy with aspirin in combination with a $\mathrm{P}_{2} \mathrm{Y}_{12}$ receptor inhibitor for the prevention of recurrent ischemic events. ${ }^{5-10}$ These guidelines now include ticagrelor, in addition to prasugrel or clopidogrel, as $\mathrm{P} 2 \mathrm{Y}_{12}$ receptor inhibitor options. ${ }^{5-10}$ No specific guideline recommends one specific $\mathrm{P} 2 \mathrm{Y}_{12}$ receptor inhibitor over another; however, the European Society of Cardiology guidelines do state that either 
prasugrel or ticagrelor are preferred over clopidogrel due to their rapid onset of action, greater potency, and superiority over clopidogrel in large outcome trials. ${ }^{10}$ The purpose of this review will be to discuss the most recently approved $\mathrm{P} 2 \mathrm{Y}_{12}$ receptor inhibitor, ticagrelor, which is the only reversible agent available in the class.

\section{Methodology}

A PubMed search was conducted to identify studies published from 1950 to November 2012 using the search terms ticagrelor, antiplatelet, ACS, myocardial infarction (MI), and PCI. Clinical outcome studies were limited to those conducted in adult humans published in English that evaluated the use of ticagrelor for cardiac indications of ACS (unstable angina [UA], non-ST elevation MI [NSTEMI], or ST elevation MI [STEMI]). Similar methodology was used to identify key pharmacokinetic and pharmacodynamic studies; however, cardiac indications were expanded to include ACS and patients with coronary artery disease (CAD). References of identified articles were reviewed for additional pertinent articles or meeting abstracts. Ticagrelor was cross-referenced with the ClinicalTrials.gov database and internet search engines to determine its investigational clinical study status. The authors excluded from the review clinical outcome trials evaluating ticagrelor in patients with stable CAD or other noncardiac indications.

\section{Pharmacokinetics}

Ticagrelor, a reversible $\mathrm{P}_{2} \mathrm{Y}_{12}$ inhibitor, is highly protein bound and does not require metabolic activation. ${ }^{11}$ On average, the median time to maximum concentration of ticagrelor is approximately 2 hours for healthy volunteers and patients with CAD and is slightly extended at 3 hours for patients with ACS. ${ }^{12-18}$ The half-life of ticagrelor is 7-8.5 hours and 8.5-10 hours for its main active metabolite (AR-C124910XX), with excretion through the urine and feces. ${ }^{12,13}$ Ingestion of food has a minimal effect on the pharmacokinetic profile of ticagrelor and its major metabolite, thus can be taken without regard to meals. ${ }^{19}$ Table 1 summarizes the pharmacokinetic and pharmacodynamic properties of ticagrelor, prasugrel, and clopidogrel. ${ }^{20-22}$

Ticagrelor has been investigated in patients with severe renal impairment (creatinine clearance $<30 \mathrm{~mL} /$ minute) and was shown to not significantly impact the pharmacokinetic or dynamic properties of the drug, and therefore no dose adjustments are required. ${ }^{20,23}$ Ticagrelor is not currently recommended for patients undergoing dialysis. Results from an ongoing study to evaluate the use of ticagrelor in this patient population should provide information about its use with hemodialysis. ${ }^{24}$

Due to the extensive hepatic metabolism of ticagrelor, evaluation of the impact hepatic impairment has on the pharmacokinetics is warranted. A study of patients with mild hepatic impairment (Child-Pugh Class A) found increased exposure to both ticagrelor and its major metabolite, but this increase was determined not to be clinically significant. ${ }^{25}$ Ticagrelor has not been evaluated in patients with moderate or severe hepatic impairment, thus its use is contraindicated. $^{20}$

Most published pharmacokinetic studies have been completed in healthy, young, Caucasian male subjects. A study evaluating the impact of age and gender on the pharmacokinetic parameters of ticagrelor found that exposure was increased in elderly subjects (aged $\geq 65$ years) and women, but these increases were clinically insignificant. ${ }^{26}$ Studies are currently ongoing investigating the pharmacokinetic

Table I Pharmacokinetic and pharmacodynamic properties of $\mathrm{P}_{2} \mathrm{Y}_{12}$ inhibitors ticagrelor, prasugrel, and clopidogrel ${ }^{20-22}$

\begin{tabular}{|c|c|c|c|}
\hline & Ticagrelor $^{20}$ & Prasugrel $^{21}$ & Clopidogrel $^{22}$ \\
\hline Class & Triazolopyrimidine & Thienopyridine & Thienopyridine \\
\hline Reversible & Yes & No & No \\
\hline Maintenance dosing & Twice daily & Once daily & Once daily \\
\hline Prodrug & No, active drug & $\begin{array}{l}\text { Yes, one-step process to } \\
\text { get to active metabolite }\end{array}$ & $\begin{array}{l}\text { Yes, two-step process to } \\
\text { get to active metabolite }\end{array}$ \\
\hline Time to maximum concentration & I.3-2 hours & 30 minutes & $30-60$ minutes \\
\hline $\begin{array}{l}\text { Time to peak platelet inhibition } \\
\text { following loading dose }\end{array}$ & $\mathrm{I}-2$ hours & $2-4$ hours & 4-6 hours \\
\hline Half-life & $7-8.5$ hours & 7 hours & 6 hours \\
\hline Metabolism & CYP3A4/5 & $\begin{array}{l}\text { CYP3A4 (major) } \\
\text { CYP2B6 } \\
\text { CYP2C } 9 / 2 \mathrm{CI} 9 \text { (minor) }\end{array}$ & $\begin{array}{l}\text { CYP2CI9 (major) } \\
\text { CYP3A4 } \\
\text { CYP2B6 } \\
\text { CYPIA2 }\end{array}$ \\
\hline Mode of excretion & Urine, feces & Urine, feces & Urine, feces \\
\hline
\end{tabular}

Abbreviation: CYP, cytochrome P450. 
profile of ticagrelor in Asian, African American, Hispanic, and American Indian patients. ${ }^{27-31}$

\section{Drug interactions}

Ticagrelor is metabolized by cytochrome P450 3A4 (CYP3A4) and CYP3A5 enzymes, with CYP3A4 predominately responsible for the metabolism of the drug. ${ }^{11,20}$ In vitro studies indicate that ticagrelor may be a weak inhibitor of CYP3A4; however, this has not proven to be clinically significant. ${ }^{20,32}$ Use with strong CYP3A4 inhibitors (eg, ritonavir) is contraindicated due to the risk of increased exposure. Coadministration with moderate CYP3A4 inhibitors (eg, diltiazem) should be used with caution. ${ }^{20}$ Due to the risk of decreased exposure and subtherapeutic antiplatelet effects, the concomitant use of CYP3A4 inducers (eg, rifampin) is not recommended. ${ }^{20}$ Ticagrelor is also a substrate and weak inhibitor of P-glycoprotein. Caution should be exercised with potent inhibitors of P-glycoprotein (eg, quinidine) as no studies have been completed to evaluate concomitant administration with ticagrelor. Ticagrelor given in combination with digoxin led to increased exposure to digoxin with no change to ticagrelor exposure. Administration of ticagrelor with P-glycoprotein-dependent drugs with narrow therapeutic indexes should be carefully monitored. ${ }^{20}$ The manufacturer recommends administration of ticagrelor with a low maintenance dose of aspirin, no greater than $100 \mathrm{mg}$ daily, due to better clinical outcomes seen with lower doses used in the PLATO (Platelet Inhibition and Patient Outcomes) trial. ${ }^{20,33}$ This capped dose of aspirin coupled with health care providers informing patients about the risk of bleeding, is mandated by the US Food and Drug Administration's (FDA) Risk Evaluation and Mitigation Strategies program. ${ }^{20,34}$

\section{Pharmacodynamics}

Ticagrelor has more consistent and increased platelet inhibition as compared to clopidogrel. ${ }^{18}$ The specifics of the onset of platelet inhibition and duration of inhibition of both ticagrelor and clopidogrel were investigated in the ONSET/ OFFSET (A Study of the Onset and Offset of Antiplatelet Effects Comparing Ticagrelor, Clopidogrel, and Placebo With Aspirin) study via light transmittance aggregometry (LTA), VerifyNow ${ }^{\circledR}$ (Accumetrics, San Diego, CA, USA), and vasodilator-stimulated phosphoprotein phosphorylation assay in patients with stable CAD. Greater platelet inhibition was seen $0.5,1,2,4,8$, and 24 hours after the loading doses of each agent and at the end of the maintenance dose phase of the study at 6 weeks $(P<0.0001$ at all time periods). Two hours following the loading dose, $98 \%$ of subjects in the ticagrelor group had $>50 \%$ platelet inhibition compared to $31 \%$ in the clopidogrel group and $90 \%$ of subjects in the ticagrelor group had $>70 \%$ platelet inhibition compared to $16 \%$ in the clopidogrel group ( $P<0.0001$ for both comparisons). The study found that the offset of ticagrelor was also more rapid, with similar platelet inhibition on day three of ticagrelor compared to day five of clopidogrel. Similarly, platelet inhibition of ticagrelor at day five and clopidogrel at day seven were similar to placebo. ${ }^{16}$

In DISPERSE (Dose Confirmation Study Assessing Antiplatelet Effects of AZD6140 Versus Clopidogrel in NSTEMI) and DISPERSE-2, the platelet inhibition of ticagrelor and clopidogrel were evaluated via optimal aggregometry in patients with stable atherosclerosis. Ticagrelor exhibited maximal platelet inhibition 2-4 hours postdose (90\%-95\%), whereas platelet inhibition with clopidogrel was minimal during this timeframe (60\%). ${ }^{15}$ DISPERSE- 2 compared the antiplatelet effect of ticagrelor in patients previously exposed to clopidogrel and those that were clopidogrel naïve. Ticagrelor produced greater platelet inhibition regardless of previous exposure to clopidogrel and to an extent similar to that of the DISPERSE trial. ${ }^{35}$

The RESPOND (A Study of the Antiplatelet Effects Comparing Ticagrelor With Clopidogrel Responders and Nonresponders) study investigated the response to ticagrelor in patients with stable $\mathrm{CAD}$ who were identified as responders or nonresponders to a $300 \mathrm{mg}$ loading dose of clopidogrel. Responsiveness was based on adenosine diphosphate-induced platelet aggregation measured before and 6-8 hours after the dose. Nonresponders were identified when the absolute change in platelet aggregation was $\leq 10 \%$. Inhibition of platelet aggregation (via LTA, VerifyNow, and vasodilator-stimulated phosphoprotein phosphorylation assay) was significantly greater in nonresponders treated with ticagrelor compared to clopidogrel $(P<0.05)$. Platelet inhibition decreased in patients switched from ticagrelor to clopidogrel and increased in those switched from clopidogrel to ticagrelor. This was demonstrated with ticagrelor's ability to overcome nonresponsiveness to clopidogrel with a $>10 \%,>30 \%$, and $>50 \%$ decrease in platelet aggregation from baseline in $100 \%, 75 \%$, and $13 \%$ of patients, respectively. ${ }^{14}$

A PLATO substudy assessed platelet inhibition (via LTA, VerifyNow, and vasodilator-stimulated phosphoprotein phosphorylation assay) of ticagrelor compared to clopidogrel in patients with ACS. As with previous studies, ${ }^{14,16,35}$ ticagrelor inhibited platelet reactivity to a greater extent than clopidogrel for both the loading and maintenance dose. 
Proton pump inhibitor (PPI) use resulted in higher platelet reactivity for clopidogrel (maximum LTA response to adenosine diphosphate $20 \mu \mathrm{M}$ with a PPI 55\% versus $39 \%$ without a PPI; $P=0.007)$, whereas there was no effect in those that received ticagrelor (maximum LTA response with a PPI 29\% versus $27 \%$ without a PPI; $P=0.68) .{ }^{17}$

The antiplatelet effect of ticagrelor compared to prasugrel was evaluated in 55 patients with STEMI undergoing PCI using the VerifyNow assay and Multiplate ${ }^{\circledR}$ analyzer (Dynabyte Informationssysteme, Munich, Germany) up to 5 days after randomization. ${ }^{36}$ The authors hypothesized that ticagrelor would have a faster onset than prasugrel due to the fact that prasugrel requires metabolic activation, whereas ticagrelor does not. The primary endpoint of platelet reactivity at 1 hour did not differ significantly between ticagrelor and prasugrel (257.3 platelet reaction units [PRU] versus 231.3 PRU; $P=0.2$ ) or through hours two, six, and 24. However, at day five, platelet reactivity was lower with ticagrelor compared to prasugrel (25.6 PRU versus 50.3 PRU; $P=0.01$ ). Ticagrelor was not superior to prasugrel during the first 24 hours of STEMI and the authors theorized these results could have been influenced by impaired drug absorption in the setting of STEMI. The authors caution that the improvement of platelet inhibition at day five with ticagrelor over prasugrel should not be translated to a reduction in ischemic events or an increased risk of bleeding episodes. ${ }^{36}$

Only one pharmacodynamic study has been published to date directly comparing ticagrelor to prasugrel in ACS patients identified as having high platelet reactivity while on clopidogrel following PCI ${ }^{37}$ Patients naïve to clopidogrel or on $75 \mathrm{mg}$ maintenance dose for $<7$ days were given a $600 \mathrm{mg}$ loading dose or not reloaded if they were on clopidogrel for $>7$ days. Platelet reactivity to clopidogrel was assessed 24 hours after PCI using the VerifyNow assay. Patients were identified as having high on-treatment platelet reactivity (HTPR) when the resulting value was $\geq 235$ PRU. This cutoff point has been linked to post-PCI ischemic risk. ${ }^{38}$ Patients were then randomized to either ticagrelor $90 \mathrm{mg}$ twice daily or prasugrel $10 \mathrm{mg}$ daily for 15 days with a crossover, with no washout period, to the alternate therapy for another 15 days. Assessments were conducted at 15 days and 30 days. Platelet reactivity at the end of the two treatment periods was lower for ticagrelor (32.9 PRU; 95\% confidence interval [CI] 18.7-47.2) compared to prasugrel (101.3 PRU; $95 \%$ CI 86.8-115.7) with a least square means difference of -68.3 PRU (95\% CI -88.6 to $-48.1 ; P<0.001)$. No ticagrelor patients had HTPR at the end of the study compared to prasugrel $(0 \%$ versus $2.4 \% ; P=0.5)$ and no patients in either group had a major bleeding event. The authors caution that the HTPR cutoff point that was used has only been evaluated during therapy with thienopyridines and may differ for treatment with direct-acting $\mathrm{P} 2 \mathrm{Y}_{12}$ receptor inhibitors. The study was also not powered to assess the relationship between the pharmacodynamic results and clinical outcomes. ${ }^{37}$

There are three more platelet reactivity trials analyzing ticagrelor in $\mathrm{ACS}^{39-42}$ and five platelet reactivity studies identifying low responders to clopidogrel prior to therapy with ticagrelor ${ }^{43-46}$ using prospective, randomized control study designs. The ACS studies evaluating platelet reactivity alone seek to actively compare it to the intravenous antiplatelet drug tirofiban in NSTEMI, ${ }^{40}$ the standard ticagrelor loading dose to a high loading dose of $600 \mathrm{mg}$ clopidogrel, ${ }^{41}$ using either ticagrelor standard loading dose or high loading dose of clopidogrel in combination with the direct thrombin inhibitor bivalidrudin, ${ }^{39}$ or in comparison to prasugrel in STEMI patients undergoing PCI. ${ }^{42}$ Studies evaluating ticagrelor in ACS patients identified as low responders to clopidogrel using initial platelet reactivity will compare using a higher ticagrelor loading dose of $360 \mathrm{mg}$ in STEMI ${ }^{43}$ with a hyporesponsiveness cutoff value of $\mathrm{PRU} \geq 208$ or another comparing ticagrelor to prasugrel using a different hyporesponsiveness cutoff value as $\geq 468 \mathrm{AU} /$ minute through multiple electrode aggregometry. ${ }^{45}$ One study seeking to evaluate clinical outcomes at 1 year will enroll PCI patients with diabetes identified as low responders to clopidogrel with a hyporesponsiveness cutoff value of PRU $\geq 208$ and will switch them to either ticagrelor or give an additional $300 \mathrm{mg}$ clopidogrel loading dose and continue maintenance doses with these agents for 1 year. ${ }^{44}$ Another interesting study evaluating 1 year clinical outcomes will enroll STEMI patients undergoing PCI who are then randomized to platelet reactivity guided modification of therapy compared to standard dual antiplatelet regimen of standard low-dose aspirin and clopidogrel $75 \mathrm{mg}$ daily with no on-treatment platelet reactivity testing. ${ }^{46}$ Patients enrolled in the platelet reactivity guided group will be assessed for low response to aspirin and clopidogrel using multiple electrode aggregometry and low responders to aspirin will receive $200 \mathrm{mg}$ for 30 days and low response to clopidogrel will receive ticagrelor $90 \mathrm{mg}$ twice daily for 1 year. Results from these studies using platelet reactivity testing will help provide more information on the utility of using these tests in low responders to clopidogrel and if modification of $\mathrm{P} 2 \mathrm{Y}_{12}$ receptor inhibitors may affect clinical outcomes.

There are other ongoing studies to evaluate what pleiotropic properties may exist beyond platelet reactivity. 
Ticagrelor will be studied compared to prasugrel or clopidogrel to determine their effects on adenosine-induced coronary vasodilatory response, ${ }^{47}$ endothelial function, ${ }^{48,49}$ effect on intracoronary electrocardiogram or chest wall motion, ${ }^{50}$ and even its use in combination with intracoronary morphine and the effect on infarct size..$^{51}$

\section{Pharmacogenomics}

A limitation of the conventional thienopyridine $\mathrm{P} 2 \mathrm{Y}_{12}$ receptor inhibitors is the fact that both clopidogrel and prasugrel are prodrugs requiring hepatic metabolism via various CYP isoenzymes to convert to their active metabolites. ${ }^{4,5}$ In particular, clopidogrel requires a two-step process for hepatic metabolism, in which the CYP2C19 isoenzyme is responsible for more than half of the first-step formation. There are at least three major genetic polymorphisms of the CYP2C19 isoenzyme. CYP2C19*1 corresponds to normal function metabolism and CYP2C19*2 and *3 are loss-of-function alleles accounting for $85 \%$ and $99 \%$ of reduced function alleles in Caucasians and Asians, respectively., ${ }^{5,22,52}$ A patient with two loss-of-function alleles is referred to as a "poor metabolizer." Package labeling for clopidogrel was updated to include a boxed warning informing health care providers of its potential for diminished effectiveness and risk for higher cardiovascular event rates in poor metabolizers of CYP2C19 isoenzyme. It states that genotyping is available and alternative treatment or treatment strategies could be considered in those identified as CYP2C19 poor metabolizers. ${ }^{22}$ The American College of Cardiology Foundation and American Heart Association (AHA) also released a clopidogrel clinical alert statement addressing the FDA's boxed warning and emphasized that clinicians must be aware that genetic variability in CYP enzymes can alter clopidogrel metabolism, affecting its inhibition of platelet function, and clinical outcomes. However, similar to the FDA, they did not mandate or require genetic testing to allow for flexibility in clinical decisions. They suggest that genetic testing could be used in patients at moderate or high risk for poor outcomes (ie, undergoing elective, high-risk PCI procedure) to determine if the patient is a poor metabolizer and may not benefit from clopidogrel. ${ }^{53}$

Prasugrel requires a single CYP-dependent step for conversion to its active metabolite predominantly through CPY3A4 and CYP2B6, thus not impacting patients with CYP2C19 polymorphisms. ${ }^{54}$ Observational studies have demonstrated no significant decrease in plasma concentrations of prasugrel or platelet inhibition activity in carriers of at least one loss-of-function allele of the CYP2C19 isoenzyme. ${ }^{55,56}$
Ticagrelor does not require transformation to an active metabolite and thus would avoid any loss of platelet inhibition activity that could be present in the presence of a lossof-function CYP2C19 allele.

The AHA NSTEMI/UA guidelines give a Class IIb recommendation to consider platelet function testing to determine platelet inhibitory response when on $\mathrm{P} 2 \mathrm{Y}_{12}$ inhibitor therapy or genotyping for CYP2C19 loss-of-function variant, but only if the results of the testing may alter management of therapy. ${ }^{5}$ The AHA PCI guidelines give a Class IIb recommendation to consider genetic testing to identify a patient who may be predisposed to inadequate platelet inhibition with clopidogrel and consider using an alternative $\mathrm{P} 2 \mathrm{Y}_{12}$ inhibitor such as prasugrel or ticagrelor. ${ }^{6}$

There are three genetic studies underway to evaluate ticagrelor in ACS patients. ${ }^{57-59}$ One study seeks to enroll patients identified with both HTPR using standard-dose clopidogrel and with a loss-of-function allele CYP2C19*2 and assign them to standard maintenance doses of ticagrelor or prasugrel or higher maintenance dose of clopidogrel $150 \mathrm{mg}$ daily for 1 month and evaluate platelet reactivity and major cardiac outcomes. ${ }^{57}$ Another study will evaluate the utility of genetic testing, in which the control group will have no genetic testing done and receive conventional therapy with clopidogrel compared to the intervention group utilizing genetic testing to identify those with or without two loss-of-function alleles (CYP2C19*2 and *3); the loss-of-function cohort will switch to ticagrelor and evaluate major cardiac outcomes at 1 year. ${ }^{59}$ One last study similarly seeks to evaluate the utility of genetic testing where the control group receives no genetic testing and standard therapy of ticagrelor, prasugrel, or clopidogrel at the physician's discretion compared to an algorithmbased modification of $\mathrm{P} 2 \mathrm{Y}_{12}$ receptor inhibitor therapy based on genetic testing identifying loss-of-function alleles CYP2C19*2 or ABCB-1 C. ${ }^{58}$ The study protocol states that ABCB-1 C carriers have been found to have reduced clopidogrel absorption and higher risk for ischemic adverse events if treated with clopidogrel. The study does not publish the phenotype-genotype $\mathrm{P} 2 \mathrm{Y}_{12}$ algorithm; however, patients are maintained on their antiplatelet therapy for 1 year when platelet reactivity and major cardiac and bleeding outcomes will be evaluated. These studies will help provide further information on the utility of genetic testing and even the utilization of the combination of genetic testing and HTPR identified through point-of-care assays in the potential for more personalized medical use of $\mathrm{P} 2 \mathrm{Y}_{12}$ inhibitors. 


\section{Clinical outcome studies of ticagrelor in ACS}

Ticagrelor was evaluated in an early prospective, randomized, double-blind, Phase II DISPERSE-2 study in 990 patients with NSTEMI (Table 2) ${ }^{60}$ Participants were randomized to ticagrelor $90 \mathrm{mg}$ twice daily, $180 \mathrm{mg}$ twice daily, or clopidogrel $300 \mathrm{mg}$ followed by $75 \mathrm{mg}$ daily for up to 3 months. Patients in the ticagrelor group were also randomized to receive a $270 \mathrm{mg}$ loading dose of ticagrelor or no loading dose. The primary objective was to assess the safety and tolerability of ticagrelor versus clopidogrel in addition to aspirin. The primary endpoint was major and minor bleeding through 4 weeks. Major and minor bleeding was 8.1\% for clopidogrel, $9.8 \%$ for ticagrelor $90 \mathrm{mg}$, and $8.0 \%$ for ticagrelor $180 \mathrm{mg}(P=0.43$ and $P=0.96$, respectively, versus clopidogrel). Major bleeding rates were $6.9 \%$ for clopidogrel, $7.1 \%$ for ticagrelor $90 \mathrm{mg}$, and $5.1 \%$ for ticagrelor $180 \mathrm{mg}$ ( $P=0.91$ and $P=0.35$, respectively, versus clopidogrel). There were also nonsignificant favorable trends for decreased rates of MI in the ticagrelor group (5.6\% for clopidogrel, $3.8 \%$ for ticagrelor $90 \mathrm{mg}$, and $2.5 \%$ for ticagrelor $180 \mathrm{mg}$; $P=0.41$ and $P=0.06$, respectively, versus clopidogrel). Nonhemorrhagic adverse effects were comparable between clopidogrel, ticagrelor $90 \mathrm{mg}$, and ticagrelor $180 \mathrm{mg}$ except for differences in rates of dyspnea, diarrhea, hypotension, and asymptomatic ventricular pauses $\geq 2.5$ seconds. Specifically, the rate of dyspnea was significantly higher for ticagrelor $180 \mathrm{mg}$ compared to clopidogrel $(15.8 \%$ versus $6.4 \% ; P<0.002)$ as was the incidence of ventricular pauses with ticagrelor $180 \mathrm{mg}$ compared to clopidogrel ( $7.9 \%$ versus $4.3 \% ; P=0.14)$. Ticagrelor $90 \mathrm{mg}$ twice daily had similar efficacy and safety compared to clopidogrel while ticagrelor $180 \mathrm{mg}$ twice daily had worse safety compared to clopidogrel. Thus, the dose of ticagrelor $90 \mathrm{mg}$ twice daily was pursued further in clinical development.

\section{PLATO study}

The most published clinical outcome study to date with ticagrelor was the PLATO trial (Table 2). ${ }^{32}$ This was a prospective, randomized, double-blind, double-dummy Phase III study that evaluated the effect of ticagrelor (180 mg loading dose and then $90 \mathrm{mg}$ twice daily) compared to clopidogrel (300-600 mg loading dose then $75 \mathrm{mg}$ daily) for 6-12 months in 18,624 ACS patients. ${ }^{32}$ Ticagrelor was superior to clopidogrel with a significant reduction in the primary composite endpoint of death from vascular causes, MI, or stroke $(9.8 \%$ versus $11.7 \%$; hazard ratio [HR] $0.84 ; 95 \%$ CI $0.77-0.92$; $P<0.001)$. In addition, the study found that the ticagrelor group had significantly lower rates of $\mathrm{MI}$ alone (5.8\% versus $6.9 \%$; HR $0.85 ; 95 \%$ CI $0.75-0.95 ; P=0.005$ ), death from vascular causes ( $4.0 \%$ versus $5.1 \%$; HR 0.79; 95\% CI 0.69-0.91; $P=0.001)$, and all cause mortality $(4.5 \%$ versus $5.9 \%$; HR $0.78 ; 95 \%$ CI $0.69-0.89 ; P<0.001)$ compared to clopidogrel. However, the rate of stroke was similar between the two groups (1.5\% ticagrelor versus 1.3\% clopidogrel; HR 1.17; 95\% CI $0.91-1.52 ; P=0.22)$. The PLATO trial utilized two definitions of bleeding, both thrombolysis in MI (TIMI) and trialspecific PLATO bleeding, which captured more events than TIMI bleeding. There was no difference in the primary safety endpoint of major PLATO bleeding between ticagrelor and clopidogrel (11.6\% versus 11.2\%; HR 1.04; 95\% CI 0.95-1.13; $P=0.43)$. Ticagrelor patients did experience more major PLATO bleeding unrelated to coronary artery bypass graft (CABG) when compared to clopidogrel $(4.5 \%$ versus $3.8 \%$; HR 1.19; 95\% CI 1.02-1.38; $P=0.03)$. The ticagrelor group also had more fatal intracranial bleeding events $(0.1 \%$ versus $0.01 \% ; P=0.02)$ than the clopidogrel group. The ticagrelor group also had numerically more intracranial bleeding events, but it was statistically nonsignificant $(0.3 \%$ versus $0.2 \%$; HR 1.87 ; $95 \%$ CI $0.98-3.58 ; P=0.06$ ). Major and minor bleeding combined was also greater in the ticagrelor group $(16.1 \%$ versus $14.6 \%$; HR $1.11 ; 95 \%$ CI $1.03-1.20 ; P=0.008)$. The ticagrelor group also experienced significantly more dyspnea (13.8\% versus $7.8 \%$; HR 1.84; 95\% CI 1.69-2.02; $P<0.001$ ) leading to a higher discontinuation rate in the ticagrelor group than the clopidogrel group ( $0.9 \%$ versus $0.1 \%$; HR $6.12 ; 95 \%$ CI 3.41-11.01; $P<0.001)$. Ticagrelor was also associated with significantly more ventricular pauses ( $\geq 3$ seconds) during the first week of therapy (5.8\% versus $3.6 \% ; P=0.01)$; however, this difference dissipated at 30 days $(2.1 \%$ versus $1.7 \% ; P=0.52$ ). Analysis of other safety endpoints found that ticagrelor was associated with a rise in serum uric acid at 1 month $(14.7 \%$ versus $7 \% ; P<0.001)$ and 12 months $(15 \%$ versus $7 \% ; P<0.001$ ), which dissipated 1 month after the end of treatment. Similarly, ticagrelor was associated with a rise in serum creatinine at 1 month $(10 \%$ versus $8 \% ; P<0.001)$ and 12 months ( $11 \%$ versus $9 \% ; P<0.001)$, which dissipated 1 month after the end of treatment. Another unusual adverse effect described in the complete response review document to the FDA was a low but significant increase in the frequency of gynecomastia in men taking ticagrelor compared to clopidogrel $(0.23 \%$ versus $0.05 \%$; relative risk 4.6$) .{ }^{61}$ The use of spironolactone could have confounded these cases and no firm conclusions could be made regarding the increased frequency, thus it was recommended in the report that this be included as a labeled adverse effect. ${ }^{20,61}$ 


\section{PLATO substudies}

Multiple substudies have been conducted looking at the safety and efficacy of ticagrelor compared to clopidogrel utilizing data acquired from the PLATO trial. Such analyses have looked at the effect of ticagrelor based on specific populations of patients. These populations included patients that underwent planned invasive cardiac strategies, noninvasive medical management, presenting with STEMI, undergoing CABG, with renal dysfunction, medical history of diabetes, stroke/transient ischemic attack (TIA), $\geq 75$ years of age, and by geographic location. Substudies were also conducted to evaluate the side effects of dyspnea and ventricular pauses.

Ticagrelor was shown to be more effective and as safe as clopidogrel in 6732 patients who received a planned invasive cardiac strategy (PCI or CABG surgery) during the PLATO trial. ${ }^{62}$ Significantly fewer ticagrelor patients experienced the primary efficacy endpoint of the composite of the rate of death from cardiovascular causes, MI, or stroke compared to those assigned to clopidogrel ( $9 \%$ versus $10.7 \%$; HR 0.84 ; $95 \%$ CI $0.75-0.94 ; P=0.0025)$. Similar to the overall mortality benefit found in the entire PLATO population, ticagrelor significantly reduced the risk of all cause death $(3.4 \%$ versus $4.3 \%$; HR 0.82 ; 95\% CI 0.68-0.98; $P=0.0103$ ) and cardiovascular death $(3.9 \%$ versus $5 \%$; HR $0.82 ; 95 \%$ CI $0.68-0.98$; $P=0.025)$ compared to clopidogrel. Furthermore, the ticagrelor group experienced similar rates of Global Use of Strategies to Open Occluded Coronary Arteries (GUSTO) severe bleeding $(2.9 \%$ versus $3.2 \%$; HR 0.91 ; $95 \%$ CI $0.74-1.12$; $P=0.3785)$ and total major bleeding $(11.5 \%$ versus $11.6 \%$; HR $0.99 ; 95 \%$ CI $0.89-1.10 ; P=0.8803$ ) compared to the clopidogrel group.

The subpopulation of 3143 PLATO patients undergoing noninvasive strategies for the management of ACS was also analyzed. ${ }^{63}$ In this population, again similar beneficial results were found using ticagrelor where it significantly reduced all-cause mortality $(6.1 \%$ versus $8.2 \%$; HR $0.75 ; 95 \%$ CI $0.61-0.93 ; P=0.01)$ and fewer patients experienced the primary efficacy endpoint ( $12 \%$ versus $14.3 \%$; HR 0.85 ; $95 \%$ CI $0.73-1 ; P=0.04)$ compared to clopidogrel. There were no differences between ticagrelor and clopidogrel comparing total major $(11.9 \%$ versus $10.3 \%$; HR $1.17 ; 95 \% \mathrm{CI}$ $0.98-1.39 ; P=0.08)$ and non-CABG-related major bleeding (4\% versus $3.1 \%$; HR 1.30 ; 95\% CI $0.95-1.77$; $P=0.10$ ).

There were significant beneficial differences in secondary outcomes favoring ticagrelor over clopidogrel in 7544 participants who were found to have a STEMI in the PLATO trial. ${ }^{64}$ In this subpopulation, ticagrelor reduced the secondary composite endpoint of cardiovascular death and MI (8.4\% versus $10.2 \%$; HR 0.82 ; $95 \%$ CI $0.71-0.96$; $P=0.01)$ and the composite of all arterial thrombotic events (13.3\% versus $15 \%$; HR 0.87 ; 95\% CI $0.77-0.99 ; P=0.03$ ) compared to clopidogrel. No differences were found between the two medications related to the primary composite efficacy endpoint or major bleeding outcomes.

A small number of participants $(\mathrm{n}=1899)$ underwent CABG surgery during the PLATO trial. ${ }^{65}$ Patients receiving ticagrelor were required to discontinue it $\geq 24-72$ hours prior to surgery, and those receiving clopidogrel were required to discontinue it $\geq 5$ days prior to CABG. Results from this subpopulation demonstrated a clinical but nonsignificant reduction in the primary efficacy outcome for those participants assigned to ticagrelor $(10.6 \%)$ compared to clopidogrel (13.1\%) (HR 0.84; 95\% CI 0.60-1.16; $P=0.29$ ). However, the study found a $51 \%$ reduction in the risk of overall mortality using ticagrelor compared to clopidogrel $(4.7 \%$ versus 9.7\%; HR 0.49; 95\% CI $0.32-0.77 ; P<0.01)$ and $48 \%$ reduction in the risk of cardiovascular death $(4.1 \%$ versus $7.9 \%$; HR $0.52 ; 95 \%$ CI $0.32-0.85 ; P<0.01)$. There was no difference in surgery-related bleeding and major bleeding overall between the treatment arms. Varenhorst et al conducted an additional investigation into the mortality data from this subanalysis. ${ }^{66}$ Subclassification of vascular deaths and nonvascular deaths from this trial were independently categorized by two blinded reviewers for the ticagrelor and clopidogrel treatment groups. A total of 58 patients assigned to clopidogrel and 29 patients assigned to ticagrelor died after post-CABG randomization. Overall, clopidogrel patients were found to experience significantly more vascular deaths than their ticagrelor counterparts $(P<0.0092)$. Additionally, patients assigned to clopidogrel had more nonvascular infection-related deaths than participants in the ticagrelor treatment group up to 12 months post-CABG (clopidogrel $2.9 \%$ versus ticagrelor $1 \%$; HR 0.36 ; $95 \%$ CI $0.14-0.93$ ). The authors concluded that the differences observed with the use of ticagrelor could be explained by the medication's rapid offset of platelet inhibitory effect as well as better regulation of platelet activation in septic patients. ${ }^{66}$

Two substudies of PLATO using ticagrelor in patients with underlying renal dysfunction ${ }^{67}$ and diabetes ${ }^{68}$ were also investigated. The first of these subanalyses looked at the efficacy and safety of ticagrelor versus clopidogrel in 3237 participants with an estimated creatinine clearance $<60 \mathrm{~mL} /$ minute. Ticagrelor demonstrated improved efficacy over clopidogrel in the reduction of the primary composite efficacy outcome $(17.3 \%$ versus $22 \%$; HR $0.77 ; 95 \%$ CI $0.65-0.90 ; P<0.05)$ and overall mortality 
Table 2 Completed ticagrelor clinical outcome studies 32,60

\begin{tabular}{|c|c|c|c|}
\hline $\begin{array}{l}\text { Reference, study acronym, } \\
\text { phase of clinical trial }\end{array}$ & $\begin{array}{l}\text { Population, trial design, } \\
\text { number of patients }\end{array}$ & $\begin{array}{l}\text { Comparison groups, } \\
\text { duration }\end{array}$ & Composite efficacy endpoint \\
\hline $\begin{array}{l}\text { Cannon et al }{ }^{60} \\
\text { DISPERSE-2, phase II }\end{array}$ & $\begin{array}{l}\text { NSTEMI } \\
P, R, D B, A C \\
(n=990) \\
\text { Ticagrelor } 90 \mathrm{mg}(n=324) \text {, } \\
\text { ticagrelor } 180 \mathrm{mg}(n=323) \text {, } \\
\text { clopidogrel } 75 \mathrm{mg}(n=327)\end{array}$ & $\begin{array}{l}\text { Ticagrelor } 90 \text { mg or } 180 \mathrm{mg} \\
\text { twice daily vs clopidogrel } \\
300 \mathrm{mg} \text { LD then } 75 \mathrm{mg} \text { daily } \\
\text { All patients received ASA } \\
\text { up to } 325 \mathrm{mg} \text { initially, } \\
\text { then } 75-100 \mathrm{mg} \text { daily } \pm \\
\text { GPIlb/Illa inhibitor } \\
\text { Ticagrelor pts were sub- } \\
\text { randomized to receive } \\
\pm 270 \text { mg LD of ticagrelor } \\
\mathrm{I}, 2 \text {, or } 3 \text { months }\end{array}$ & $\begin{array}{l}\text { Secondary endpoint: composite CV death/ } \\
\text { MI/stroke at } 4 \text { weeks: ticagrelor I } 80 \mathrm{mg} \\
\text { I.9\% ( } P=0.17 \text { vs clopidogrel); ticagrelor } \\
90 \mathrm{mg} 4.3 \% \text { vs clopidogrel } 3.8 \% \\
(P=0.7 \mathrm{I}) \\
\text { Composite CV death/MI/stroke at } \\
\text { I } 2 \text { weeks: ticagrelor I } 80 \mathrm{mg} 3.5 \% \\
(P=0.12 \text { vs clopidogrel }) ; \text { ticagrelor } \\
90 \mathrm{mg} 6 \% \text { vs clopidogrel } 6.2 \% \\
(P=0.90)\end{array}$ \\
\hline
\end{tabular}

\begin{tabular}{|c|c|c|c|}
\hline $\begin{array}{l}\text { Wallentin et } \mathrm{al}^{32} \\
\text { PLATO, phase III }\end{array}$ & $\begin{array}{l}\text { ACS- NSTEMI 59\%, } \\
\text { STEMI 38\% (invasive } \\
\text { and noninvasive) } \\
P, R, D B, A C, D D \\
(n=18,624) \\
\text { Ticagrelor }(n=9333) \text {, } \\
\text { clopidogrel }(n=929 I)\end{array}$ & $\begin{array}{l}\text { Ticagrelor I } 80 \text { mg LD, } \\
\text { then } 90 \text { mg twice daily vs } \\
\text { clopidogrel } 300-600 \mathrm{mg} \\
\text { LD, then } 75 \mathrm{mg} \text { daily } \\
\text { Pts undergoing PCl after } \\
\text { randomization received an } \\
\text { additional dose of } 300 \mathrm{mg} \\
\text { clopidogrel at investigator's } \\
\text { discretion or ticagrelor } \\
90 \text { mg if PCI > } 24 \text { hours } \\
\text { post randomization } \\
\text { All pts received } \\
\text { ASA daily; if naïve to } \\
\text { ASA, then } 325 \text { mg load } \\
\text { I } 2 \text { months }\end{array}$ & $\begin{array}{l}\text { Primary: composite endpoint of death } \\
\text { from vascular causes, MI, or stroke: } \\
\text { ticagrelor } 9.8 \% \text { vs clopidogrel II.7\% } \\
\text { (HR 0.84; } 95 \% \mathrm{CI} 0.77-0.92 ; P<0.00 \mathrm{I}) \\
\text { Secondary: composite endpoint of death } \\
\text { from any cause, MI, or stroke: ticagrelor } \\
\text { I0.2\% vs clopidogrel I } 2.3 \% \text { (HR } 0.84 \text {; } \\
95 \% \mathrm{Cl} 0.77-0.92 ; P<0.00 \mathrm{I}) \\
\text { Composite endpoint of death from } \\
\text { vascular causes, MI, stroke, severe recurrent } \\
\text { ischemia, TIA, or other arterial thrombotic } \\
\text { event: ticagrelor I4.6\% vs clopidogrel I6.7\% } \\
\text { (HR 0.88; } 95 \% \mathrm{Cl} 0.8 \mathrm{I}-0.95 ; P<0.00 \mathrm{I}) \\
\text { Composite endpoint of death from any } \\
\text { vascular causes, } \mathrm{MI} \text {, or stroke in pts whom } \\
\text { invasive treatment was planned: ticagrelor } \\
8.9 \% \text { vs clopidogrel I0.6\% (HR } 0.84 ; \\
95 \% \mathrm{Cl} 0.75-0.94 ; P=0.003 \text { ) }\end{array}$ \\
\hline
\end{tabular}

Abbreviations: AC, active control; ACS, acute coronary syndrome; ASA, aspirin; CABG, coronary artery bypass grafting; Cl, confidence interval; CV, cardiovascular; CVA, cerebral vascular accident; DB, double-blind; DD, double dummy; DISPERSE 2, Dose Confirmation Study Assessing Antiplatelet Effects of AZD6I40 Versus Clopidogrel in Non-ST Elevation Myocardial Infarction-2; GPIlb/llla, glycoprotein Ilb/llla inhibitor; HR, hazard ratio; LD, loading dose; MI, myocardial infarction; NR, not reported; NSTEMI, non-ST elevation myocardial infarction; P, prospective; PCl, percutaneous coronary intervention; PLATO, Platelet Inhibition and Patient Outcomes; pts, patients; R, randomized; STEMI, ST elevation myocardial infarction; TIA, transient ischemic attack; vs, versus.

(10\% versus $14 \%$; HR $0.72 ; 95 \%$ CI $0.58-0.89 ; P<0.05$ ). The renal substudy did not analyze further outcomes as they related to specific medication therapy. However, significantly more patients with creatinine clearance $<60 \mathrm{~mL} /$ minute were on angiotensin-converting enzyme (ACE) inhibitor or angiotensin II receptor blocker (ARB) therapy on arrival. The complete response review submitted to the FDA for ticagrelor included an analysis based on concomitant ACE inhibitor or ARB therapy. ${ }^{61}$ The report further analyzed renal adverse events and found that a higher proportion of patients on concomitant ticagrelor-ARB therapy had $>50 \%$ increases in serum creatinine (11.2\% versus $7.1 \%)$, renal related adverse events (6.5\% versus $4.3 \%)$ and renal function adverse events (4.5\% versus $2.8 \%$ ) compared to clopidogrel-ARB patients. Concomitant ACE inhibitor therapy had higher rates of patients with $>50 \%$ increases in serum creatinine in both ticagrelor and clopidogrel groups, but not to the same extent as patients receiving concomitant $\mathrm{ARBs} .{ }^{61,69}$ Despite this information from the complete response review report to the FDA, the package labeling for ticagrelor specifies that no dosage adjustment is needed for patients with renal impairment, nor does it specify any drug interaction with ARBs or ACE inhibitors. ${ }^{20}$ In the substudy of 4662 patients with diabetes, those subjects assigned to ticagrelor with hemoglobin $\mathrm{A}_{1 \mathrm{c}}$ above the median $(6 \%)$ were found to have a significantly reduced primary composite efficacy endpoint (HR 0.80; 95\% CI 0.70-0.91), decreased all-cause mortality (HR 0.78; 95\% CI 0.65-0.93), and reduced stent thrombosis (HR 0.62; 95\% CI 0.39-1.0). ${ }^{68}$ It should be noted that no differences were found in bleeding outcomes in patients with kidney disease or diabetes. ${ }^{67,68}$ 


\begin{tabular}{|c|c|c|c|c|}
\hline Mortality & MI & CVA & $\begin{array}{l}\text { Stent } \\
\text { thrombosis }\end{array}$ & Bleeding \\
\hline 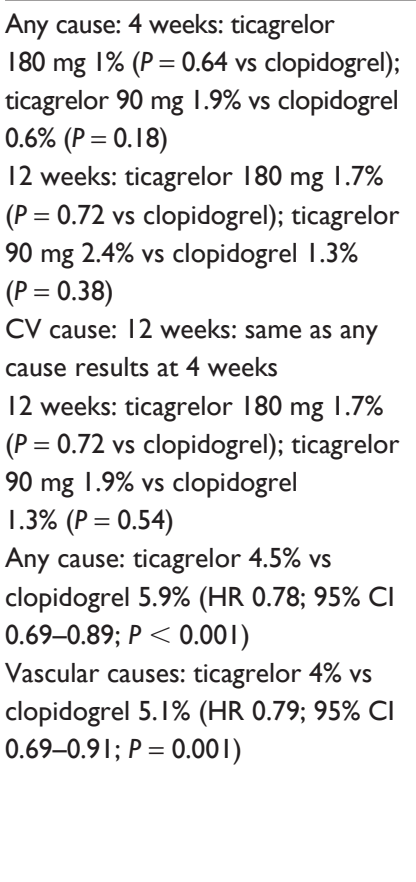 & $\begin{array}{l}4 \text { weeks: ticagrelor } \\
\text { I } 80 \mathrm{mg} \text { I\% }(P=0.047 \\
\text { vs clopidogrel); ticagrelor } \\
90 \mathrm{mg} 2.2 \% \text { vs clopidogrel } \\
3.5 \%(P=0.34) \\
\text { I } 2 \text { weeks: ticagrelor } \\
\text { I80 mg I\% ( }(P=0.047 \\
\text { vs clopidogrel) ticagrelor } \\
90 \mathrm{mg} 2.2 \% \text { vs clopidogrel } \\
3.5 \%(P=0.34)\end{array}$ & $\begin{array}{l}4 \text { weeks: ticagrelor } \\
180 \mathrm{mg} 0 \%(P=0.99 \\
\text { vs clopidogrel); } \\
\text { ticagrelor } 90 \mathrm{mg} \\
0.6 \% \text { vs clopidogrel } \\
0.3 \%(P=0.57) \\
12 \text { weeks: same } \\
\text { results at } 4 \text { weeks }\end{array}$ & $\begin{array}{l}\text { Definite: ticagrelor } \\
\text { I.3\% vs clopidogrel } \\
\text { I.9\% (HR 0.69; } \\
95 \% \mathrm{Cl} 0.50-0.91 \\
P=0.009 \text { ) }\end{array}$ & $\begin{array}{l}\text { Primary endpoint: major or minor } \\
\text { bleeding at } 4 \text { weeks: ticagrelor } \\
\text { I } 80 \mathrm{mg} 8 \% \text { ( } P=0.96 \text { vs clopidogrel); } \\
\text { ticagrelor } 90 \mathrm{mg} 9.8 \% \text { vs clopidogrel } \\
8.1 \%(P=0.43) \\
\text { Major bleeding at } 4 \text { weeks: } \\
\text { ticagrelor } 180 \mathrm{mg} 5.1 \% \text { ( } P=0.35 \text { vs } \\
\text { clopidogrel); ticagrelor } 90 \mathrm{mg} 7.1 \% \\
\text { vs clopidogrel } 6.9 \% \text { ( } P=0.9 \mathrm{I}) \\
\text { Major or minor bleeding at I } 2 \\
\text { weeks: ticagrelor I } 80 \mathrm{mg} \text { II.4\% } \\
(P=0.72 \text { vs clopidogrel); ticagrelor } \\
90 \text { mg I0.9\% vs clopidogrel } \\
9.9 \%(P=0.62) \\
\text { PLATO major bleeding: ticagrelor } \\
\text { II.6\% vs clopidogrel II.2\% (HR } \\
\text { I.04; } 95 \% \text { CI } 0.95-1.13 ; P=0.43) \\
\text { PLATO major bleeding not related } \\
\text { to CABG: ticagrelor } 4.5 \% \text { vs } \\
\text { clopidogrel } 3.8 \%(P=0.03) \\
\text { Fatal intracranial bleeding: } \\
\text { ticagrelor } 0.1 \% \text { vs clopidogrel } 0.01 \% \\
(P=0.02)\end{array}$ \\
\hline
\end{tabular}

A population subanalysis was conducted in PLATO patients with or without a previous history of stroke/TIA ${ }^{70}$ Compared to the rest of the PLATO study population, patients with a history of stroke/TIA $(\mathrm{n}=1152)$ had higher rates of MI (11.5\% versus $6 \%$, adjusted HR 1.92; 95\% CI 1.59-2.33; $P<0.0001)$, death $(10.5 \%$ versus $4.9 \%$; adjusted HR 2.18; 95\% CI 1.79-2.66; $P<0.0001)$, stroke (3.4\% versus $1.2 \%$; adjusted HR 2.90; 95\% CI 2.03-4.14; $P<0.0001)$, and intracranial bleeding $(0.8 \%$ versus $0.2 \%$; adjusted HR 3.95; $95 \%$ CI 1.82-8.55; $P=0.0005)$. A significant reduction in allcause mortality at 1 year was found in those patients receiving ticagrelor compared to clopidogrel (7.9\% versus $13 \%$; HR 0.62 ; 95\% CI $0.42-0.91$ ). However, the primary composite efficacy outcome and PLATO-defined bleeding rates were found to be similar to the PLATO trial as a whole.
An evaluation of elderly patients (defined as $\geq 75$ years of age; $\mathrm{n}=2878$ ) was conducted from the PLATO trial data. ${ }^{71}$ No clinical benefit was demonstrated with the use of ticagrelor when compared to clopidogrel in reduction of the primary efficacy endpoint $(17.2 \%$ versus $18.3 \%$; HR 0.89 ; 95\% CI 0.74-1.08). A numerical absolute reduction in all-cause mortality was observed in elderly patients who received ticagrelor treatment compared to clopidogrel (2.6\% versus $1.2 \% ; P=0.99)$. No differences were found in PLATO-derived major bleeding outcomes comparing ticagrelor to clopidogrel (14.2\% versus $13.5 \%$; HR 1.02; 95\% CI 0.82-1.27). It should be noted that the elderly population assigned to ticagrelor had a greater propensity to experience adverse drug effects including dyspnea and ventricular pauses. 
Finally, Mahaffey et al conducted a PLATO subgroup analysis looking at geographic region and clinical outcomes in patients assigned to ticagrelor and clopidogrel. Two independent statistical groups evaluated 37 prespecified baseline and postrandomization factors from the PLATO trial and found a significant interaction between treatment and region $(P=0.045)$, with North American participants (US and Canada) demonstrating a nonsignificant trend towards an unfavorable treatment effect with ticagrelor for the primary endpoint (HR 1.25; 95\% CI 0.93-1.67) compared to a favorable outcome in the other regions combined. ${ }^{32,20}$ Out of the baseline and postrandomization factors, the dose of aspirin taken concomitantly with ticagrelor was the only accounting factor found to explain the geographic differences observed in the PLATO trial. Landmark techniques and Cox regression with median maintenance dose analysis were conducted on the data and it was confirmed that ticagrelor taken in conjunction with low-dose maintenance aspirin (defined as $\leq 100 \mathrm{mg}$ /day) yielded better treatment outcomes compared with clopidogrel than those participants taking high-dose maintenance $(\geq 300 \mathrm{mg} /$ day) aspirin combined with ticagrelor. Over half of the participants in the US (53.6\%) took a median dose of aspirin $\geq 300 \mathrm{mg} /$ day compared to the rest of the world $(1.7 \%)$. A hypothesis involving greater inhibition of prostacyclin, which is known to reduce platelet reactivity, with higher aspirin doses was postulated to attenuate the treatment effects of ticagrelor. Without a strong biological justification for the exact mechanism of this interaction, the authors concluded that chance alone could not be ruled out in describing the geographic discrepancies observed in the trial results. ${ }^{33}$ The geographic differences in efficacy observed in the PLATO trial was one of the reasons for initial delay in FDA approval of ticagrelor in 2010 pending further investigation. Results from the geographic subanalysis led the FDA to include a boxed warning to health care professionals and patients warning that maintenance doses of aspirin $>100 \mathrm{mg}$ per day reduce the effectiveness of ticagrelor and should be avoided. ${ }^{20}$

Additional assessment of the side effect of dyspnea with ticagrelor was further evaluated from the PLATO and ONSET/OFFSET study populations. ${ }^{72-74} \mathrm{~A}$ substudy to evaluate the long-term effect of ticagrelor on various pulmonary function parameters was conducted on 199 patients enrolled in the PLATO trial. ${ }^{73}$ The study found no differences between ticagrelor and clopidogrel for any pulmonary function parameters after a mean treatment duration of 31 days, end of treatment (mean 211 days), and after the study drug was discontinued (mean 32 days after the last dose). The authors noted that a limitation to their substudy was the exclusion of patients with advanced lung disease; however, patients with a history of congestive heart failure and pulmonary disease were included in the main PLATO study with no specific safety concerns identified. The same lead author sought to describe the incidence of dyspnea and its association with demographic characteristics and clinical outcomes from the PLATO study population. ${ }^{72}$ Overall, significantly more patients randomized to ticagrelor reported dyspnea at any point during the study compared to the clopidogrel group ( $14.5 \%$ versus $8.7 \% ; P<0.001)$. Of these cases, only $0.4 \%$ receiving ticagrelor and $0.3 \%$ receiving clopidogrel were of severe intensity. The median onset of the symptoms of dyspnea from the start of therapy was seen earlier with ticagrelor compared to clopidogrel (23 days versus 43 days; $P<0.0001)$. More patients receiving ticagrelor discontinued the medication due to dyspnea compared to clopidogrel $(5.9 \%$ versus $1.6 \% ; P<0.0001$ ) representing $0.9 \%$ and $0.1 \%$ of treated patients, respectively. The incidence of the primary composite endpoint in patients reporting dyspnea was greater compared with those not reporting dyspnea in both ticagrelor and clopidogrel groups, primarily due to a higher incidence of MI. After exclusion of patients with dyspnea following MI, ticagrelor showed favorable trends for mortality compared to clopidogrel, similar to the overall PLATO results. Further analysis of those patients who experienced dyspnea in the first 30 days found the rate of MI after 30 days were similar between both ticagrelor- and clopidogrel-treated groups, while cardiovascular death and total mortality rates were significantly lower in the ticagrelor-treated patients. Therefore, the authors concluded that there was not any loss of treatment effect in ticagrelor-treated patients who experienced dyspnea from their post hoc analysis. ${ }^{72}$ A subanalysis from the ONSET/OFFSET study population of CAD patients also found significantly higher rates of dyspnea with ticagrelor compared to clopidogrel or placebo, which typically occurred during the first week of therapy, were mild in intensity, and most cases resolved following discontinuation of the drug. ${ }^{74}$ Three patients who were taking ticagrelor discontinued treatment as a result of the dyspnea compared to none who were taking clopidogrel or placebo. Assessment of pulmonary function tests after 6 weeks were not significantly affected in these CAD patients receiving ticagrelor. ${ }^{74}$ Discussion from the manufacturer's complete response review report to the FDA also noted that dyspnea was increased in patients on concomitant ticagrelor-ARB compared to clopidogrelARB patients (21.4\% versus 9.9\%); however, this interaction was not included in any package labeling. ${ }^{20,61,69}$ While the mechanism for ticagrelor-related dyspnea has 
not been clearly elucidated, a popular hypothesis is that ticagrelor inhibits adenosine reuptake and thereby increases extracellular adenosine concentrations. Exogenous adenosine administration is known to cause dyspnea, perhaps through activation of $\mathrm{A} 1$ receptors and resulting stimulation of pulmonary vagal $\mathrm{C}$ fibers. ${ }^{75}$ Further investigation is required to explore this hypothesis and search for other potential mechanisms. The current labeling for ticagrelor includes a warning for prescribers to inform patients of the possible side effect of shortness of breath.

The adverse effect of ventricular pauses was found from the DISPERSE trial, therefore a substudy was conducted for 2866 patients enrolled in the PLATO trial who underwent continuous electrocardiograph monitoring to analyze whether the pauses were associated with any bradycardiac events. ${ }^{76}$ From the PLATO trial, significantly more patients receiving ticagrelor experienced ventricular pauses $\geq 3$ seconds; however, these occurred less frequently at 1 month and were similar between ticagrelor and clopidogrel. Most were asymptomatic, sinoatrial in origin, and nocturnal. There were no differences between ticagrelor and clopidogrel in the incidence of clinically reported bradycardiac adverse events including syncope, pacemaker placement, and cardiac arrest during the entire study duration (median 277 days). ${ }^{76}$

\section{Ongoing clinical outcome studies of ticagrelor in ACS}

A Phase IV, prospective, randomized, double-blind study will be conducted in 1770 patients to determine the efficacy and safety of prehospital versus in-hospital initiation of ticagrelor in STEMI patients planned for PCI. ${ }^{77}$ Patients will receive ticagrelor $180 \mathrm{mg}$ loading dose either in the field or at the hospital followed by $90 \mathrm{mg}$ twice daily for 30 days. The primary outcome measures are TIMI flow Grade III of MI culprit vessel at initial angiography and ST-segment resolution up to pre-PCI $\geq 70 \%$. This study is expected to be complete by May 2013 .

A prospective, randomized, double-blind, double-dummy, Phase III study is being conducted in 800 Asian/Japanese patients to assess the safety and efficacy of ticagrelor for ACS. ${ }^{30}$ Patients will be randomized to ticagrelor $90 \mathrm{mg}$ twice daily versus clopidogrel $75 \mathrm{mg}$ daily in addition to aspirin. The primary outcomes are time to first total major bleeding event up to 12 months and time to first occurrence of event from the composite of death from vascular causes, MI, and stroke up to 12 months. This study was expected to be completed in July 2012; however, no results have been published for this study yet.
Another ongoing prospective, randomized study will evaluate the use of either 6 months or 12 months of dual antiplatelet therapy with ticagrelor and aspirin in STEMI patients who have received a drug-eluting stent. ${ }^{78}$ Patients in the 6-month group will continue aspirin alone for a further 6 months and major clinical outcomes will be assessed at time periods up to 18 months after randomization. The study plans to enroll 1100 patients with an expected completion date by December 2013 .

There are two ongoing clinical outcome studies evaluating specific types of drug-eluting stents (everolimus- or zotarolimus-eluting) using any $\mathrm{P}_{2} \mathrm{Y}_{12}$ receptor inhibitor of ticagrelor, prasugrel, or clopidogrel for 6-12 months based on risk. ${ }^{79,80}$

\section{Meta-analyses including ticagrelor}

Three meta-analyses have been conducted that include ticagrelor studies in their evaluation. ${ }^{81-83}$ One meta-analysis compared prasugrel to ticagrelor combining the results from three trials in 32,893 patients. ${ }^{81}$ Not surprisingly, the authors found that either prasugrel or ticagrelor were superior to clopidogrel for 12-month risk of death, MI, or stroke (odds ratio [OR] $0.83 ; 95 \%$ CI $0.77-0.89 ; P<0.001)$, death (OR 0.83; 95\% CI 0.74-0.93; $P=0.001$ ), MI (OR 0.79; 95\% CI $0.73-0.86 ; P<0.001$ ), and stent thrombosis (OR $0.61 ; 95 \%$ CI $0.51-0.74 ; P<0.001$ ). They found no difference between the agents for stroke or major bleeding but a significant increase in drug discontinuation for prasugrel and ticagrelor (OR 1.12; 95\% CI 1.05-1.19; $P<0.001$ ). Comparison of prasugrel versus ticagrelor found no significant differences in death, MI, stroke, or their combined composite. Prasugrel, when compared to ticagrelor, was associated with a decrease in stent thrombosis (OR 0.64; $95 \%$ CI $0.43-0.93 ; P=0.020)$. Ticagrelor was associated with a significantly lower risk of any major bleeding (OR 1.43; 95\% CI 1.10-1.85; $P=0.007)$ and major bleeding associated with bypass grafting (OR 4.30; CI 1.73-10.6; $P=0.002)$. Major bleeding not related to bypass surgery was similar between the two agents (OR 1.06; 95\% CI 0.77-1.45; $P=0.34$ ).

A second meta-analysis of seven randomized ACS trials in 58,591 patients was conducted to determine differences in ischemic and bleeding complications between standarddose clopidogrel (300 mg loading dose and $75 \mathrm{mg}$ daily) compared to the newer antiplatelet regimens ( $600 \mathrm{mg}$ loading dose clopidogrel, ticagrelor, or prasugrel). ${ }^{82}$ Similar to the previous meta-analyses, newer antiplatelet regimens significantly reduced mortality (2.9\% versus $3.4 \%$; OR $0.87 ; 95 \%$ CI $0.79-0.95 ; P=0.002)$, recurrent MI $(4.2 \%$ versus $5.2 \%$; 
OR $0.80 ; 95 \%$ CI $0.74-0.87 ; P<0.0001)$, and definite stent thrombosis ( $0.9 \%$ versus $1.7 \%$; OR $0.52 ; 95 \%$ CI $0.43-0.63$; $P<0.0001)$ compared to standard-dose clopidogrel. Newer antiplatelet regimens were not associated with an increase in major bleeding complications (5\% versus 4.7\%; OR 1.06; 95\% CI 0.96-1.17; $P=0.25$ ).

A third meta-analysis was conducted evaluating fourteen randomized trials evaluating prasugrel, ticagrelor, and highor standard-dose clopidogrel in 48,982 patients scheduled for PCI. ${ }^{83}$ The largest cohorts of patients included in the meta-analysis were from the PLATO (comparing ticagrelor to standard-dose clopidogrel), TRITON-TIMI 38 (Trial to Assess Improvement in Therapeutic Outcomes by Optimizing Platelet Inhibition With Prasugrel TIMI 38; comparing prasugrel to standard-dose clopidogrel), and CURRENTOASIS 7 (Clopidogrel Optimal Loading Dose Usage to Reduce Recurrent Events/Optimal Antiplatelet Strategy for Interventions; comparing high-dose clopidogrel to standarddose clopidogrel) trials. The direct meta-analysis found that ticagrelor, prasugrel, and high-dose clopidogrel significantly reduced the risk of MI, major adverse cardiovascular event, and stent thrombosis compared to standard-dose clopidogrel. The network meta-analysis showed that ticagrelor was associated with a nonsignificant reduction of all-cause mortality compared to prasugrel and high-dose clopidogrel. No superiority of any treatment strategy over the other was seen for cardiovascular mortality, MI, stroke, or major adverse cardiovascular event. Prasugrel was associated with a significantly lower risk for stent thrombosis (OR 0.63; 95\% CI $0.42-0.94$ ) but more major (OR $1.43 ; 95 \%$ CI 1.07-1.90) and minor (OR 1.36; 95\% CI 1.09-1.69) bleeding compared to ticagrelor. Ticagrelor was also found to exhibit a significantly lower risk of major or minor bleeding compared to high-dose clopidogrel (OR 0.81; 95\% CI 0.69-0.96). The risk of nonCABG-related major bleeding did not differ between the three $\mathrm{P} 2 \mathrm{Y}_{12}$ receptor inhibitors.

These meta-analyses suggest comparative superiority of ticagrelor, prasugrel, or high loading dose clopidogrel over standard-dose clopidogrel with a lower risk for major or minor bleeding with ticagrelor compared to prasugrel. However, these results should be weighed carefully until further data from head-to-head clinical outcome trials comparing ticagrelor with prasugrel are conducted. Unfortunately, there appears to be no large, prospective, randomized controlled studies registered to date comparing ticagrelor to prasugrel in ACS patients beyond the smaller pharmacodynamic or pharmacogenomics studies previously mentioned.

\section{Discussion}

Ticagrelor has been approved for use in Europe and Canada/ US under the trade names Brilique ${ }^{\circledR}$ and Brilinta ${ }^{\circledR}$, respectively, as dual antiplatelet therapy with aspirin for the prevention of atherothrombotic events in adults with ACS..$^{20,84,85}$ It is the most recent $\mathrm{P} 2 \mathrm{Y}_{12}$ receptor inhibitor approved for use in the US as dual antiplatelet therapy with aspirin doses $\leq 100 \mathrm{mg}$ daily. ${ }^{20}$ Providers must carefully assess each ACS patient's individual risk factors for secondary events, absolute contraindications, or precautions relative to the various $\mathrm{P}_{2} \mathrm{Y}_{12}$ receptor inhibitors, balanced with their risk of bleeding when determining the most appropriate oral antiplatelet therapy.

The newest $\mathrm{P} 2 \mathrm{Y}_{12}$ receptor inhibitor ticagrelor has the enhanced ability to reduce mortality, prevent major adverse cardiac outcomes with a low risk of major bleeding compared to clopidogrel. However, the benefits found from the PLATO study come with the cost of an increased risk of non-CABG related major bleeding, fatal intracranial bleeding, dyspnea, and early ventricular pauses compared to clopidogrel. Substudies of the PLATO trial revealed that ticagrelor continues to show mortality benefit in patients undergoing planned invasive or noninvasive strategies, $\mathrm{CABG}$, or those with renal dysfunction, diabetes, or a history of stroke or TIA. No substudies showed an increased risk of major bleeding compared to clopidogrel. Ticagrelor is the first $\mathrm{P} 2 \mathrm{Y}_{12}$ receptor inhibitor to show a mortality benefit and it has been hypothesized that this could have been secondary to the prevention of red blood cell uptake of adenosine, which may benefit myocardial blood flow, vasodilatation, cardiac preconditioning, and immunomodulation. ${ }^{72,76,85-88}$ As mentioned in the pharmacodynamics section, numerous studies are underway to determine other pleiotropic effects of ticagrelor beyond its ability to inhibit platelet aggregation.

Other properties of ticagrelor must also be taken into consideration when choosing $\mathrm{P} 2 \mathrm{Y}_{12}$ receptor inhibitor therapy. Studies with ticagrelor have revealed nonhemorrhagic adverse events not seen with other FDA-approved $\mathrm{P} 2 \mathrm{Y}_{12}$ receptor inhibitors, including dyspnea, ventricular pauses, elevations in serum creatinine and uric acid, and gynecomastia. Substudies specifically analyzing the adverse effects of dyspnea, ventricular pauses, and in patients with underlying renal dysfunction found no loss of treatment effect in ticagrelor-treated patients. Regarding these subpopulations, the PLATO study excluded patients at increased risk of bradycardiac events (eg, patients with sick sinus syndrome, second- or third-degree atrioventricular block, or bradycardiac-related syncope and not protected with a pacemaker) and those on dialysis; however, it included patients 
with asthma, chronic obstructive pulmonary disease, and other respiratory diseases. Another unique adverse effect seen with ticagrelor was elevations in uric acid levels. In the complete response review report to the FDA, the proposed mechanism for elevated uric acid was that adenosine blocks uric acid transport channel activity and that ticagrelor may prevent red blood cell reuptake of adenosine. ${ }^{61}$ Therefore, it should be used with caution in patients with severe respiratory disorders, those at risk for bradycardiac events, or those with a history of hyperuricemia, gouty arthritis, or uric acid nephropathy. No dosage adjustment is required for those patients with renal dysfunction; however, it should not be used in patients on dialysis. ${ }^{20}$ Ticagrelor is metabolized by the liver and impaired hepatic function can increase the risk of bleeding or other adverse effects. No dosage adjustment is required in patients with mild hepatic impairment; however, it should not be used in patients with severe liver disease since no studies have been conducted in this population. ${ }^{20}$

Ticagrelor is the first and only reversible inhibitor of $\mathrm{P} 2 \mathrm{Y}_{12}$ that does not require metabolic activation. Lack of metabolic activation may explain the shorter time necessary to reach peak platelet inhibition compared to clopidogrel and prasugrel. This is an important aspect to consider in patients undergoing cardiac catheterization with unknown anatomy and the potential for CABG. In the PLATO study, ticagrelor was held for 24-72 hours prior to surgery while it was recommended to wait 5 days in the clopidogrel group; however, no significant difference was found for CABG-related bleeding between ticagrelor compared to clopidogrel. ${ }^{32}$ Likewise, Gurbel et al found that the percent of platelet inhibition of ticagrelor 3 days after discontinuation was the same as 5 days after clopidogrel discontinuation. ${ }^{16}$ The manufacturer's package insert for the US product recommends stopping ticagrelor $\geq 5$ days prior to surgery, ${ }^{20}$ however, the package insert for the European product recommends stopping it 7 days prior to surgery ${ }^{84}$ Both the AHA NSTEMI/UA and STEMI guidelines (Class I recommendation, Class IIb) and ESC NSTEMI/ UA guidelines (Class IIa recommendation) give a strong recommendation to stop both clopidogrel and ticagrelor 5 days prior to nonemergent surgery (including $\mathrm{CABG}$ ) and prasugrel 7 days prior to allow for dissipation of the antiplatelet effect. ${ }^{5,78}$ However, the ESC guidelines on myocardial revascularization clarify that ticagrelor was discontinued 48-72 hours before CABG surgery in the PLATO trial. ${ }^{9}$ The most recently published 2013 AHA STEMI guidelines further state to discontinue both clopidogrel and ticagrelor $\geq 24$ hours before urgent on-pump CABG (Class I recommendation) if possible or 24 hours before urgent off-pump
CABG if the benefit outweighs the risk of bleeding (Class IIb recommendation).?

In a noncompliant patient, adherence to ticagrelor could be problematic since it is dosed twice daily and has a more rapid offset than other thienopyridines. The antiplatelet effects of ticagrelor drop more precipitously than clopidogrel 8-24 hours postdose, but the inhibition of platelet aggregation is maintained at a level comparable or greater than clopidogrel over this time period. However, by 48 hours postdose, the inhibition of platelet aggregation is less than that seen with clopidogrel and by 72 hours postdose and is about $20 \%$, which is comparable to that seen with 5-7 days after discontinuation of clopidogrel. ${ }^{16,75}$ If doses are missed, the rapid offset of ticagrelor may potentially carry greater thrombotic risk for such patients; however, no studies have been conducted to evaluate clinical outcomes related to the offset of action of ticagrelor. One meta-analysis showed that patients receiving ticagrelor or prasugrel were more likely to discontinue these agents compared to clopidogrel. ${ }^{81}$ Therefore, it is important to discuss adherence to the dosing regimen with patients and necessary planning, such as carrying extra tablets during extended times away from home. The cost of ticagrelor could also impact medication adherence. A coupon card is available for ticagrelor in the US; however, clopidogrel is generic and may have better prescription insurance coverage imparting lower out-of-pocket costs for patients. Studies to evaluate long-term adherence and clinical outcomes with ticagrelor therapy compared to other $\mathrm{P}_{2} \mathrm{Y}_{12}$ inhibitors from real world settings through private or federal medical and prescription insurance claims databases should be conducted in the future.

Studies have been conducted to evaluate the costeffectiveness of ticagrelor using PLATO study data and comparing it to genotype-driven clopidogrel. The first of these studies was a base case analysis that sought to determine the event rates, health care costs (in 2010 Euros), and health-related quality of life during 12 months of therapy with ticagrelor or generic clopidogrel from a health care perspective, applying units costs and life tables from a Swedish setting. ${ }^{89}$ For the study, the daily cost of generic clopidogrel $€ 0.06$ and ticagrelor $€ 2.21$ was applied. The results showed that the mean cumulative health care costs were $€ 96$ higher with ticagrelor-treated patients (95\% CI -360 to 553; $P=0.679)$. Overall, the mean study drug costs were $€ 590$ higher with ticagrelor (95\% CI 582-590; $P<0.0001$ ). Results from the base case analysis showed that ticagrelor was associated with a quality adjusted life year (QALY) gain of 0.1316 at an incremental cost of $€ 362$, yielding a cost 
per QALY gained of $€ 2753$ when compared to generic clopidogrel. The cost per QALY gained was $€ 2372$. Despite the higher drug cost of ticagrelor, its cost per QALY was below the generally accepted threshold for cost-effectiveness. From this study, ticagrelor was found to be cost-effective compared to clopidogrel from the health care perspective. ${ }^{89}$ The second cost-effectiveness analysis compared ticagrelor with genotype-driven therapy with clopidogrel in a cohort of Medicare patients with ACS. ${ }^{90}$ The study found an incremental cost-effectiveness ratio of USD10,059 per QALY with ticagrelor therapy compared with genotype-driven clopidogrel therapy over a 5-year period. These studies both suggest ticagrelor is a cost-effective alternative despite a higher drug acquisition cost compared to clopidogrel.

Individualization of antiplatelet therapy based on platelet reactivity and/or genetic testing to identify patients that may benefit from the use of ticagrelor are areas under current investigation. These studies may provide information on the utility of these approaches to modify $\mathrm{P} 2 \mathrm{Y}_{12}$ receptor inhibitor selection to improve clinical outcomes. ${ }^{44,46,58,59}$ Currently, randomized clinical trials have shown that the use of agents such as ticagrelor and prasugrel have stronger and more predictable antiplatelet effects than clopidogrel with resultant reduction in ischemic events. ${ }^{32,91}$ However, clinical trial evidence is currently lacking as to whether therapy management based on antiplatelet response translates to improved clinical outcomes. Studies that have investigated patients with HTPR have concluded that adjusting the dose of the $\mathrm{P} 2 \mathrm{Y}_{12}$ agent based on this high reactivity did not result in a statistically significant reduction in clinical outcomes. ${ }^{92,93}$ In addition, another study has been done comparing the choice of $\mathrm{P} 2 \mathrm{Y}_{12}$ agent in patients with HTPR and has found positive outcome results utilizing platelet reactivity-guided therapy, but due to low event numbers it is unclear if these results are indeed significant. ${ }^{94}$

\section{Conclusion}

Dual antiplatelet therapy with aspirin now includes the choices of clopidogrel, prasugrel, or ticagrelor for patients with ACS. Ticagrelor has proven to be superior to clopidogrel by reducing mortality and other major cardiac outcomes with an increased risk of non-CABG-related major bleeding and fatal intracranial bleeding. It is important for providers to carefully assess many patient-specific factors, including the risk of thrombosis or bleeding, concomitant disease states, nonhemorrhagic adverse effects, medication adherence, and cost implications for the patient, and plan for urgent surgery when choosing the most appropriate $\mathrm{P} 2 \mathrm{Y}_{12}$ receptor inhibitor.
It is also important to understand the potential that ticagrelor may provide in situations where patients are likely not to respond to clopidogrel or whom may not be candidates for prasugrel therapy.

\section{Disclosure}

The authors report no conflicts of interest in this work.

\section{References}

1. World Health Organization. Top Ten Causes of Death. Geneva: World Health Organization; 2011. Available from: http://www.who.int/ mediacentre/factsheets/fs310_2008.pdf. Accessed December 14, 2012.

2. Behan MW, Chew DP, Aylward PE. The role of antiplatelet therapy in the secondary prevention of coronary artery disease. Curr Opin Cardiol. 2010;25(4):321-328.

3. Marczewski MM, Postula M, Kosior D. Novel antiplatelet agents in the prevention of cardiovascular complications - focus on ticagrelor. Vasc Health Risk Manag. 2010;6:419-429.

4. Siller-Matula JM, Krumphuber J, Jilma B. Pharmacokinetic, pharmacodynamic and clinical profile of novel antiplatelet drugs targeting vascular diseases. Br J Pharmacol. 2010;159(3):502-517.

5. Jneid H, Anderson JL, Wright RS, et al. 2012 ACCF/AHA focused update of the guideline for the management of patients with unstable angina/ non-ST-elevation myocardial infarction (updating the 2007 guideline and replacing the 2011 focused update): a report of the American College of Cardiology Foundation/American Heart Association Task Force on Practice Guidelines. Circulation. 2012;126(7):875-910.

6. Levine GN, Bates ER, Blankenship JC, et al. 2011 ACCF/AHA/ SCAI guideline for percutaneous coronary intervention: a report of the American College of Cardiology Foundation/American Heart Association Task Force on Practice Guidelines and the Society for Cardiovascular Angiography and Interventions. Circulation. 2011;124(33):e574-e651.

7. O'Gara PT, Kushner FG, Ascheim DD, et al. 2013 ACCF/AHA guideline for the management of ST-elevation myocardial infarction: a report of the American College of Cardiology Foundation/American Heart Association Task Force on Practice Guidelines. J Am Coll Cardiol. 2013;61(4):e78-e140.

8. Hamm CW, Bassand JP, Agewall S, et al. ESC guidelines for the management of acute coronary syndromes in patients presenting without persistent ST-segment elevation: the task force for the management of acute coronary syndromes (ACS) in patients presenting without persistent ST-segment elevation of the European Society of Cardiology (ESC). Eur Heart J. 2011;32(23):2999-3054.

9. Wijns W, Kolh P, Danchin N, et al. Guidelines on myocardial revascularization. Eur Heart J. 2010;31(20):2051-2055.

10. Steg PG, James SK, Atar D, et al. ESC guidelines for the management of acute myocardial infarction in patients presenting with ST-segment elevation. Eur Heart J. 2012;33(20):2569-2619.

11. Zhou D, Andersson TB, Grimm SW. In vitro evaluation of potential drug-drug interactions with ticagrelor: cytochrome $\mathrm{P} 450$ reaction phenotyping, inhibition, induction, and differential kinetics. Drug Metab Dispos. 2011;39(4):703-710.

12. Teng R, Oliver S, Hayes MA, Butler K. Absorption, distribution, metabolism, and excretion of ticagrelor in healthy subjects. Drug Metab Dispos. 2010;38(9):1514-1521.

13. Teng R, Butler K. Pharmacokinetics, pharmacodynamics, tolerability and safety of single ascending doses of ticagrelor, a reversibly binding oral $\mathrm{P}_{2} \mathrm{Y}_{12}$ receptor antagonist, in healthy subjects. Eur J Clin Pharmacol. 2010;66(5):487-496.

14. Gurbel PA, Bliden KP, Butler K, et al. Response to ticagrelor in clopidogrel nonresponders and responders and effect of switching therapies: the RESPOND study. Circulation. 2010;121(10):1188-1199. 
15. Husted S, Emanuelsson H, Hepinstall S, Sandset PM, Wickens M, Peters G. Pharmacodynamics, pharmacokinetics, and safety of the oral reversible $\mathrm{P}_{2} \mathrm{Y}_{12}$ antagonist AZD6140 with aspirin in patients with atherosclerosis: a double-blind comparison to clopidogrel with aspirin. Eur Heart J. 2006;27(9):1038-1047.

16. Gurbel PA, Bliden KP, Butler K, et al. Randomized double-blind assessment of the ONSET and OFFSET of the antiplatelet effects of ticagrelor versus clopidogrel in patients with stable coronary disease: the ONSET/OFFSET study. Circulation. 2009;120(25): $2577-2585$.

17. Storey RF, Angiolillo DJ, Patil SB, et al. Inhibitory effects of ticagrelor compared with clopidogrel on platelet function in patients with acute coronary syndromes: the PLATO (Platelet Inhibitions and Patient Outcomes) PLATELET substudy. J Am Coll Cardiol. 2010;56(18): 1456-1462.

18. Butler K, Teng R. Pharmacokinetics, pharmacodynamics, safety and tolerability of multiple ascending doses of ticagrelor in healthy volunteers. Br J Clin Pharmacol. 2010;70(1):65-77.

19. Teng R, Mitchell PD, Butler K. Lack of significant food effect on the pharmacokinetics of ticagrelor in healthy volunteers. $J$ Clin Pharm Ther. 2012;37(4):464-468.

20. Brilinta ${ }^{\circledR}$ (ticagrelor) [package insert]. Wilmington, DE: AstraZeneca Pharmaceuticals LP; 2013.

21. Effient ${ }^{\mathrm{TM}}$ (prasugrel) [package insert]. Indianapolis, IN: Eli Lilly and Co; 2012.

22. Plavix ${ }^{\circledR}$ (clopidogrel bisulfate) [package insert]. Bridgewater, NJ: Sanofi-Aventis US; 2011.

23. Butler K, Teng R. Pharmacokinetics, pharmacodynamics, and safety of ticagrelor in volunteers with severe renal impairment. JClin Pharmacol. 2012;52(9):1388-1398.

24. University of Patras. Ticagrelor in clopidogrel resistant patients undergoing chronic hemodialysis. In: ClinicalTrials.gov [website on the Internet]. Bethesda, MD: US National Library of Medicine; 2012 [updated February 2, 2012]. Available from: http://clinicaltrials. gov/show/NCT01511471. NLM identifier: NCT01511471. Accessed December 14, 2012.

25. Butler K, Teng R. Pharmacokinetics, pharmacodynamics, and safety of ticagrelor in volunteers with mild hepatic impairment. $J$ Clin Pharmacol. 2011;51(7):978-987.

26. Teng R, Mitchell P, Butler K. Effect of age and gender on pharmacokinetics and pharmacodynamics of a single ticagrelor dose in healthy individuals. Eur J Clin Pharmacol. 2012;68(8):1175-1182.

27. AstraZeneca. An Asian study to assess the properties and profile of ticagrelor in patients with stable coronary artery disease. In: ClinicalTrials.gov [website on the Internet]. Bethesda, MD: US National Library of Medicine; 2010 [updated April 13, 2012]. Available from: http:// clinicaltrials.gov/show/NCT01118325. NLM identifier: NCT01118325. Accessed December 14, 2012.

28. AstraZeneca. A pharmacodynamics study with ticagrelor in African American patients. In: ClinicalTrials.gov [website on the Internet]. Bethesda, MD: US National Library of Medicine; 2012 [updated February 4, 2013]. Available from: http://clinicaltrials.gov/ show/NCT01523392. NLM identifier: NCT01523392. Accessed December 14, 2012.

29. AstraZeneca. A pharmacodynamic study with ticagrelor in Hispanic patients. In: ClinicalTrials.gov [website on the Internet]. Bethesda, MD: US National Library of Medicine; 2012 [updated February 4, 2013]. Available from: http://clinicaltrials.gov/show/NCT01523366. NLM identifier: NCT01523366. Accessed December 14, 2012.

30. AstraZeneca. Study to assess safety and efficacy of ticagrelor (AZD6140) versus clopidogrel in Asian/Japanese patients with non-ST or ST elevation acute coronary syndromes (ACS). In: ClinicalTrials. gov [website on the Internet]. Bethesda, MD: US National Library of Medicine; 2011 [updated August 17, 2012]. Available from: http:// clinicaltrials.gov/show/NCT01294462. NLM identifier: NCT01294462. Accessed December 14, 2012.
31. Rapid City Regional Hospital; AstraZeneca. Antiplatelet effects of ticagrelor versus clopidogrel in American Indian patients. In: ClinicalTrials.gov [website on the Internet]. Bethesda, MD: US National Library of Medicine; 2012. Available from: http://clinicaltrials.gov/ show/NCT01706510. NLM identifier: NCT01706510. Accessed December 14, 2012.

32. Wallentin L, Becker RC, Budaj A, et al. Ticagrelor versus clopidogrel in patients with acute coronary syndromes. $N$ Engl J Med. 2009;361(11): 1045-1057.

33. Mahaffey KW, Wojdyla DM, Carroll K, et al. Ticagrelor compared with clopidogrel by geographic region in the Platelet Inhibition and Patient Outcomes (PLATO) trial. Circulation. 2011;124(5):544-554.

34. Brilinta ${ }^{\mathrm{TM}}$ (ticagrelor) tablets REMS. [homepage on the Internet]. Available from: http://www.brilintarems.com. Wilmington, DE: AstraZeneca Pharmaceuticals LP; 2011. Accessed December 14, 2012.

35. Storey RF, Husted S, Harrington RA, et al. Inhibition of platelet aggregation by AZD6140, a reversible oral $\mathrm{P} 2 \mathrm{Y}_{12}$ receptor antagonist, compared with clopidogrel in patients with acute coronary syndromes. J Am Coll Cardiol. 2007;50(19):1852-1856.

36. Alexopoulos D, Xanthopoulou I, Gkizas V, et al. Randomized assessment of ticagrelor versus prasugrel antiplatelet effects in patients with ST-segment-elevation myocardial infarction. Circ Cardiovasc Interv. 2012;5(6):797-804.

37. Alexopoulos D, Galati A, Xanthopoulou I, et al. Ticagrelor versus prasugrel in acute coronary syndrome patients with high on-clopidogrel platelet reactivity following percutaneous coronary intervention: a pharmacodynamic study. J Am Coll Cardiol. 2012;60(3):193-199.

38. Bonello L, Tantry US, Marcucci R, et al. Consenus and future directions on the definition of high on-treatment platelet reactivity to adenosine diphosphate. J Am Coll Cardiol. 2010;56(12):919-933.

39. Badimon JJ; AstraZeneca. Antithrombotic effects of ticagrelor versus clopidogrel. In: ClinicalTrials.gov [website on the Internet]. Bethesda, MD: US National Library of Medicine; 2012. Available from: http:// clinicaltrials.gov/show/NCT01642238. NLM identifier: NCT01642238. Accessed December 14, 2012.

40. Pusan National University Yangsan Hospital; AstraZeneca. Comparison of antiplatelet effect of ticagrelor vs tirofiban in patients with non-ST elevation acute coronary syndrome (TE-CLOT). In: ClinicalTrials. gov [website on the Internet]. Bethesda, MD: US National Library of Medicine; 2012 [updated December 16, 2012]. Available from: http:// clinicaltrials.gov/show/NCT01660373. NLM identifier: NCT01660373. Accessed December 14, 2012.

41. AstraZeneca. Ad hoc percutaneous coronary intervention study in acute coronary syndrome patients. In: ClinicalTrials.gov [website on the Internet]. Bethesda, MD: US National Library of Medicine; 2012 [updated January 15, 2013]. Available from: http://clinicaltrials. gov/show/NCT01603082. NLM identifier: NCT01603082. Accessed December 14, 2012.

42. Careggi Hospital. Rapid activity of platelet inhibitor drugs study (RAPID). In: ClinicalTrials.gov [website on the Internet]. Bethesda, MD: US National Library of Medicine; 2012 [updated January 13, 2012]. Available from: http://clinicaltrials.gov/show/NCT01510171. NLM identifier: NCT01510171. Accessed December 14, 2012.

43. University of Patras. Standard ( $180 \mathrm{mg}$ ) versus double $(360 \mathrm{mg})$ loading dose of ticagrelor in patients with ST-elevation myocardial infarction (STEMI), undergoing primary percutaneous coronary intervention (PCI). In: ClinicalTrials.gov [website on the Internet]. Bethesda, MD: US National Library of Medicine; 2012 [updated April 10, 2012]. Available from: http://clinicaltrials.gov/show/NCT01575795. NLM identifier: NCT01575795. Accessed December 14, 2012.

44. Rabin Medical Center. Effect of modifying anti-platelet treatment to ticagrelor in patients with diabetes and low response to clopidogrel (MATTIS-D). In: ClinicalTrials.gov [website on the Internet]. Bethesda, MD: US National Library of Medicine; 2012 [updated July 17, 2012]. Available from: http://clinicaltrials.gov/show/NCT01643031. NLM identifier: NCT01643031. Accessed December 14, 2012. 
45. Deutsches Herzzentrum Muenchen. Intracoronary stenting and antithrombotic regimen: adjusting antiplatelet treatment in patients based on platelet function testing (ISAR ADAPT PF). In: ClinicalTrials.gov [website on the Internet]. Bethesda, MD: US National Library of Medicine; 2011. Available from: http://clinicaltrials.gov/ show/NCT01456364. NLM identifier: NCT01456364. Accessed December 14, 2012.

46. Clinical Center of Serbia. On-treatment platelet reactivity-guided therapy modification for ST-segment elevation myocardial infarction (PLATFORM). In: ClinicalTrials.gov [website on the Internet]. Bethesda, MD: US National Library of Medicine; 2012 [updated November 30, 2012]. Available from: http://clinicaltrials.gov/ show/NCT01739556. NLM identifier: NCT01739556. Accessed December 14, 2012.

47. University of Patras. Differential effect of ticagrelor versus prasugrel on the adenosine-induced coronary vasodilatory responses in patients with acute coronary syndrome undergoing percutaneous coronary intervention. In: ClinicalTrials.gov [website on the Internet]. Bethesda, MD: US National Library of Medicine; 2012 [updated January 21, 2013]. Available from: http://clinicaltrials.gov/show/NCT01642966. NLM identifier: NCT01642966. Accessed December 14, 2012.

48. Johannes Gutenberg University Mainz. Endothelium, stenting, and antiplatelet therapy (EST) - clopidogrel, prasugrel, ticagrelor study. In: ClinicalTrials.gov [website on the Internet]. Bethesda, MD: US National Library of Medicine; 2012 [updated October 11, 2012]. Available from: http://clinicaltrials.gov/show/NCT01700322. NLM identifier: NCT01700322. Accessed December 14, 2012.

49. Assistance Publique Hopitaux De Marseille. Evaluation of ticagrelor antiplatelet and pleiotropic effects in patients undergoing percutaneous coronary intervention for an acute coronary syndrome. In: ClinicalTrials.gov [website on the Internet]. Bethesda, MD: US National Library of Medicine; 2012 [updated June 20, 2012]. Available from: http:// clinicaltrials.gov/show/NCT01626534. NLM identifier: NCT01626534. Accessed December 14, 2012.

50. University of Texas Southwestern Medical Center; AstraZeneca. A trial comparing the ischemic preconditioning effects of ticagrelor and clopidogrel in humans (ETCH). In: ClinicalTrials.gov [website on the Internet]. Bethesda, MD: US National Library of Medicine; 2012 [updated December 4, 2012]. Available from: http://clinicaltrials. gov/show/NCT01743937. NLM identifier: NCT01743937. Accessed December 14, 2012.

51. Hyeon-Cheol Gwon. Ticagrelor and intracoronary morphine in patients undergoing primary percutaneous coronary intervention. In: ClinicalTrials.gov [website on the Internet]. Bethesda, MD: US National Library of Medicine; 2012 [updated November 29, 2012]. Available from: http:// clinicaltrials.gov/show/NCT01738100. NLM identifier: NCT01738100. Accessed December 14, 2012.

52. Mega JL, Close SL, Wiviott SD, et al. Cytochrome P-450 polymorphisms and response to clopidogrel. N Engl J Med. 2009;360(4): 354-362.

53. Holmes DR Jr, Dehmer GJ, Kaul S, Leifer D, O'Gara PT, Stein CM. ACCF/AHA clopidogrel clinical alert: approaches to the FDA "boxed warning": a report of the American College of Cardiology Foundation Task Force on Clinical Expert Consensus Documents and the American Heart Association. Circulation. 2010;122(5):537-557.

54. Chandrasekar S, Loomba R, Shah P, Arora R. Ideal antiplatelet therapy for coronary artery disease: focus on adenosine diphosphate receptor inhibitors. Am J Ther. April 23, 2011; [Epub ahead of print.]

55. Mega JL, Close SL, Wiviott SD, et al. Cytochrome P450 genetic polymorphisms and the response to prasugrel: relationship to pharmacokinetic, pharmacodynamics, and clinical outcomes. Circulation. 2009;119(19):2553-2560.

56. Varenhorst C, James S, Erlinge D, et al. Genetic variation of CYP2C19 affects both pharmacokinetic and pharmacodynamics responses to clopidogrel but not prasugrel in aspirin-treated patients with coronary artery disease. Eur Heart J. 2009;30(14):1744-1752.
57. University of Roma La Sapienza. High clopidogrel dose versus prasugrel and ticagrelor in high reactive stable patients (TRIPLETE RESET). In: ClinicalTrials.gov [website on the Internet]. Bethesda, MD: US National Library of Medicine; 2012 [updated December 4, 2012]. Available from: http://clinicaltrials.gov/show/NCT01543932. NLM identifier: NCT01543932. Accessed December 14, 2012.

58. Italian Society of Invasive Cardiology. Customized choice of oral P2 $\mathrm{Y}_{12}$ receptor blocker (GENE-MATRIX). In: ClinicalTrials.gov [website on the Internet]. Bethesda, MD: US National Library of Medicine; 2011 [updated November 5, 2012]. Available from: http://clinicaltrials. gov/show/NCT01477775. NLM identifier: NCT01477775. Accessed December 14, 2012

59. Mayo Clinic. Tailored antiplatelet therapy following PCI (TAILORPCI). In: ClinicalTrials.gov [website on the Internet]. Bethesda, MD: US National Library of Medicine; 2012. Available from: http://clinicaltrials. gov/show/NCT01742117. NLM identifier: NCT01742117. Accessed December 14, 2012

60. Cannon CP, Husted S, Harrington RA, et al. Safety, tolerability, and initial efficacy of AZD6140, the first reversible oral adenosine diphosphate receptor antagonist, compared with clopidogrel, in patients with non-ST-segment elevation acute coronary syndrome: primary results of the DISPERSE-2 trial. J Am Coll Cardiol. 2007;50(19):1844-1851.

61. Center for Drug Evaluation and Research. Ticagrelor: Complete Response Review Addenum. Silver Spring, MD: US Food and Drug Administration; 2011. Available from: http://www.accessdata.fda.gov/drugsatfda_docs/ nda/2011/022433Orig1s000MedR.pdf. Accessed January 5, 2013.

62. Cannon CP, Harrington RA, James S, et al. Comparison of ticagrelor with clopidogrel in patients with a planned invasive strategy for acute coronary syndromes (PLATO): a randomized double-blind study. Lancet. 2010;375(9711):283-293.

63. James SK, Row MT, Cannon CP, et al. Ticagrelor versus clopidogrel in patients with acute coronary syndromes intended for non-invasive management: substudy from prospective randomized Platelet Inhibition and Patient Outcomes (PLATO) trial. BMJ. 2011;342:d3527.

64. Steg PG, James S, Harrington RA, et al. Ticagrelor versus clopidogrel in patients with ST-elevation acute coronary syndromes intended for reperfusion with primary percutaneous coronary intervention: a Platelet Inhibition and Patient Outcomes (PLATO) trial subgroup analysis. Circulation. 2010;122(21):2131-2141.

65. Held C, Asenblad N, Bassand JP, et al. Ticagrelor versus clopidogrel in patients with acute coronary syndromes undergoing coronary artery bypass surgery: results from the PLATO (Platelet Inhibition and Patient Outcomes) trial. J Am Coll Cardiol. 2011;57(6):672-684.

66. Varenhorst C, Alstrom U, Scirica B, et al. Factors contributing to the lower mortality with ticagrelor compared with clopidogrel in patients undergoing coronary artery bypass surgery. J Am Coll Cardiol. 2012; 60(17):1623-1630.

67. James S, Budaj A, Aylward P, et al. Ticagrelor versus clopidogrel in acute coronary syndromes in relation to renal function: results from the Platelet Inhibition and Patient Outcomes (PLATO) trial. Circulation. 2010;122(11):1056-1067.

68. James S, Angiolillo DJ, Cornel JH, et al. Ticagrelor vs clopidogrel in patients with acute coronary syndromes and diabetes: a substudy from the Platelet Inhibition and Patient Outcomes (PLATO) trial. Eur Heart J. 2010;31(24):3006-3016.

69. DiNicolantonio JJ, Serebruany VL. Angiotensin receptor blockers worsen renal function and dyspnea on ticagrelor: a potential ticagrelorangiotensin receptor blocker interaction? Clin Cardiol. 2012;35(11): 647-648.

70. James SK, Storey RF, Khurmi NS, et al. Ticagrelor versus clopidogrel in patients with acute coronary syndromes and a history of stroke or transient ischemic attack. Circulation. 2012;125(23):2914-2921.

71. Husted S, James S, Becker RC, et al. Ticagrelor versus clopidogrel in elderly patients with acute coronary syndromes: a substudy from the prospective randomized Platelet Inhibition and Patient Outcomes (PLATO) trial. Circ Cardiovasc Qual Outcomes. 2012;5(5):680-688. 
72. Storey RF, Becker RC, Harrington RA, et al. Characterization of dyspnea in PLATO study patients treated with ticagrelor or clopidogrel in its association with clinical outcomes. Eur Heart J. 2011;32(23):2945-2953.

73. Storey FR, Becker RC, Harrington RA, et al. Pulmonary function in patients with acute coronary syndrome treated with ticagrelor or clopidogrel (from the Platelet Inhibition and Patient Outcomes [PLATO] pulmonary function substudy). Am J Cardiol. 2011;108(11): 1542-1546.

74. Storey RF, Bliden KP, Patil SB, et al. Incidence of dyspnea and assessment of cardiac and pulmonary function in patients with stable coronary artery disease receiving ticagrelor, clopidogrel, or placebo in the ONSET/OFFSET study. J Am Coll Cardiol. 2010;56(3):185-193.

75. Nawarskas JJ, Snowden SS. Critical appraisal of ticagrelor in the management of acute coronary syndrome. Ther Clin Risk Manag. 2011;7: 473-488.

76. Scirica BM, Cannon CP, Emanuelsson H, et al. The incidence of bradyarrhythmias and clinical bradyarrhythmic events in patients with acute coronary syndromes treated with ticagrelor or clopidogrel in the PLATO (Platelet Inhibition and Patient Outcomes) trial: results of the continuous electrocardiographic assessment substudy. J Am Coll Cardiol. 2011;57(19):1908-1916.

77. AstraZeneca. A 30 day study to evaluate efficacy and safety of prehospital versus in-hospital initiation of ticagrelor therapy in STEMI patients planned for percutaneous coronary intervention (PCI) (ATLANTIC). In: ClinicalTrials.gov [website on the Internet]. Bethesda, MD: US National Library of Medicine; 2011 [updated December 20, 2012]. Available from: http://clinicaltrials.gov/show/NCT01347580. NLM identifier: NCT01347580. Accessed December 14, 2012.

78. Maasstad Hospital. Randomized, open label trial of 6 months versus 12 months DAPT after drug-eluting stent in STEMI (DAPT-STEMI). In: ClinicalTrials.gov [website on the Internet]. Bethesda, MD: US National Library of Medicine; 2011 [updated December 17, 2012]. Available from: http://clinicaltrials.gov/show/NCT01459627. NLM identifier: NCT01459627. Accessed December 14, 2012.

79. Boston Scientific Corporation. PROMUS Element Plus US post-approval study. In: ClinicalTrials.gov [website on the Internet]. Bethesda, MD: US National Library of Medicine; 2012 [updated October 17, 2012]. Available from: http://clinicaltrials.gov/show/NCT01589978. NLM identifier: NCT01589978. Accessed December 14, 2012.

80. Marco Valgimigli. Zotarolimus-eluting Endeavor Sprint stent in uncertain DES candidates (ZEUS) study. In: ClinicalTrials.gov [website on the Internet]. Bethesda, MD: US National Library of Medicine; 2011 [updated October 6, 2012]. Available from: http://clinicaltrials. gov/show/NCT01385319. NLM identifier: NCT01385319. Accessed December 14, 2012.

81. Biondi-Zoccai G, Lotrionte M, Agostoni P, et al. Adjusted indirect comparison meta-analysis of prasugrel versus ticagrelor for patients with acute coronary syndromes. Int J Cardiol. 2011;150(3):325-331.

82. Navarese EP, Verdoia M, Schaffer A, et al. Ischaemic and bleeding complications with new, compared to standard, ADP-antagonist regimens in acute coronary syndromes: a meta-analysis of randomized trials. QJM. 2011;104(7):561-569.
83. Steiner S, Moertl D, Chen L, Coyle D, Wells GA. Network meta-analysis of prasugrel, ticagrelor, high- and standard-dose clopidogrel in patients scheduled for percutaneous coronary interventions. Thromb Haemost. 2012;108(2):318-327.

84. European Medicines Agency. Brilique: Summary of Product Characteristics. London: European Medicines Agency; 2010. Available from: http://www.ema.europa.eu/docs/en_GB/document_library/ EPAR_-_Product_Information/human/001241/WC500100494.pdf. Accessed December 14, 2012.

85. Brilinta ${ }^{\circledR}$ (ticagrelor) [product monograph]. Mississauga, ON AstraZeneca Canada; 2011.

86. Serebruany VL. Adenosine release: a potential explanation for the benefits of ticagrelor in the Platelet Inhibition and Clinical Outcomes trial. Am Heart J. 2011;161(1):1-4.

87. Agewall S, Badimon L, Drouet L, et al. Oral antiplatelet agents in ACS: from pharmacology to clinical differences. Fundam Clin Pharmacol. 2011;25(5):564-571.

88. Scneider DJ. Mechanisms potentially contributing to the reduction in mortality associated with ticagrelor therapy. J Am Coll Cardiol. 2011;57(6):685-687.

89. Nikolic E, Janzon M, Hauch O, et al. Cost-effectiveness of treating acute coronary syndrome patients with ticagrelor for 12 months: results from the PLATO study. Eur Heart J. 2013;34(3):220-228.

90. Crespin DJ, Federspiel JJ, Biddle AK, Jonas DE, Rossi JS. Ticagrelor versus genotype-driven antiplatelet therapy for secondary prevention after acute coronary syndrome: a cost-effectiveness analysis. Value Health. 2011;14(4):483-491.

91. Mehta SR, Tanguay JF, Eikelboom JW, et al. Double-dose versus standard-dose clopidogrel and high-dose versus low-dose aspirin in individuals undergoing percutaneous coronary intervention for acute coronary syndromes (CURRENT-OASIS 7): a randomised factorial trial. Lancet. 2010;376(9748):1233-1243.

92. Price MJ, Berger PB, Teirstein PS, et al. Standard- vs high-dose clopidogrel based on platelet function testing after percutaneous coronary intervention: the GRAVITAS randomized trial. JAMA. 2011;305(11):1097-1105.

93. Collet JP, Cuisset T, Range G, et al. Bedside monitoring to adjust antiplatelet therapy for coronary stenting. $N$ Engl J Med. 2012;367(22): 2100-2109.

94. Trenk D, Stone GW, Gawaz M, et al. A randomized trial of prasugrel versus clopidogrel in patients with high platelet reactivity on clopidogrel after elective percutaneous coronary intervention with implantation of drug-eluting stents: results of the TRIGGER-PCI (Testing Platelet Reactivity In Patients Undergoing Elective Stent Placement on Clopidgorel to Guide Alternative Therapy With Prasugrel) study. J Am Coll Cardiol. 2012;59(24):2159-2164.
Clinical Pharmacology: Advances and Applications

\section{Publish your work in this journal}

Clinical Pharmacology: Advances and Applications is an international, peer-reviewed, open access journal publishing original research, reports, reviews and commentaries on all areas of drug experience in humans. The manuscript management system is completely online and includes a very quick and fair peer-review system, which is all easy to use.

\section{Dovepress}

Visit http://www.dovepress.com/testimonials.php to read real quotes from published authors. 